Universidad de Lima

Escuela de Posgrado

Maestría en Derecho Empresarial

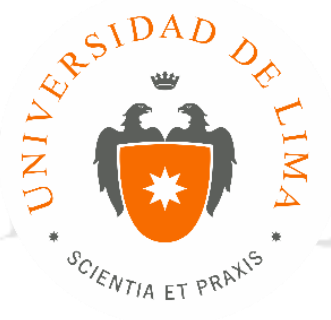

\title{
EL TERCERO REGISTRAL EN EL DERECHO SOCIETARIO Y SU PROTECCIÓN JURÍDICA
}

Trabajo de investigación para optar el Grado Académico de Maestro en

Derecho Empresarial

\section{Marco Antonio Becerra Sosaya}

Código 19890070

$$
\text { Lima - Perú }
$$

Marzo del 2016 


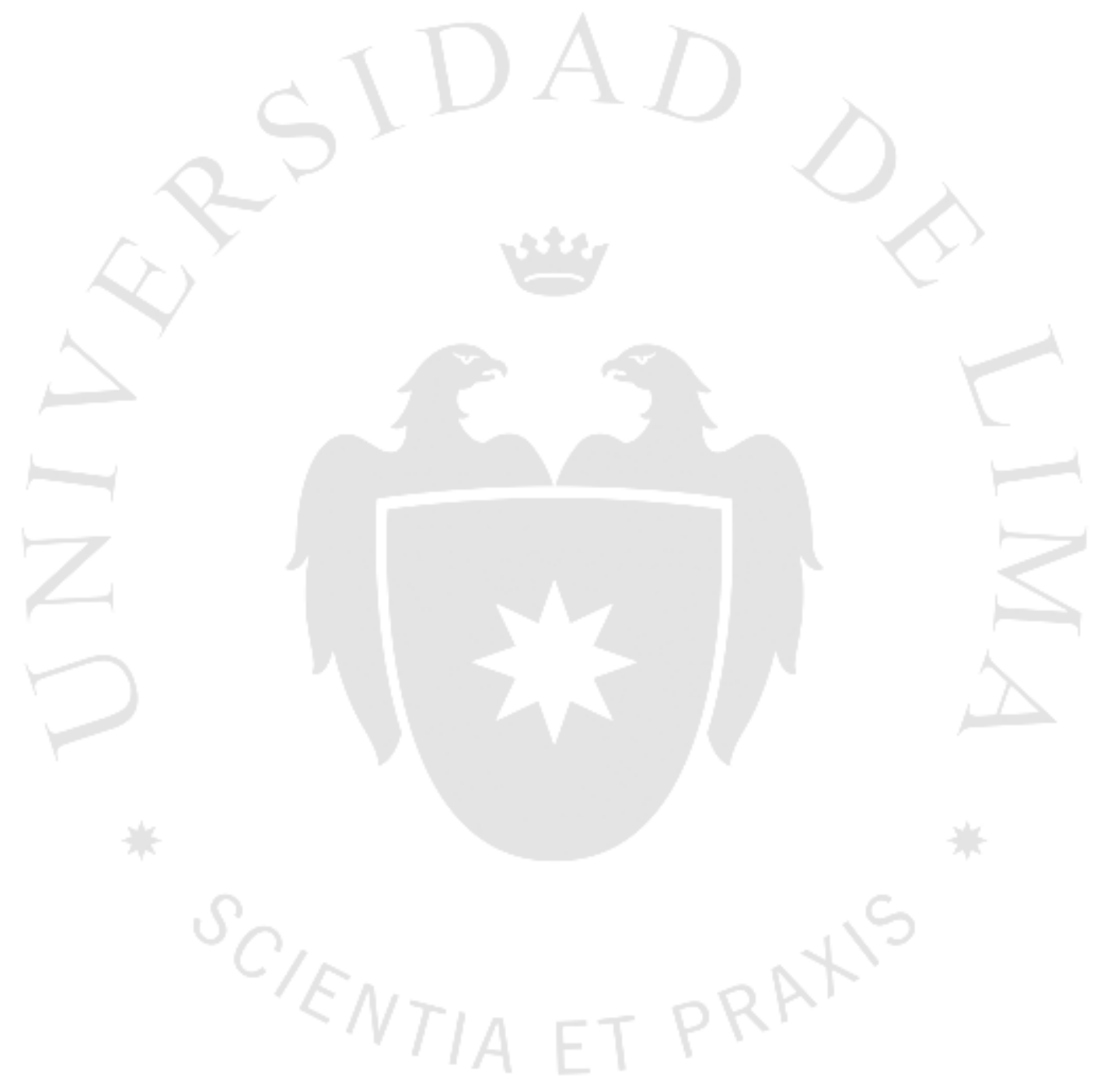




\section{EL TERCERO REGISTRAL EN EL DERECHO SOCIETARIO Y SU PROTECCIÓN JURÍDICA}




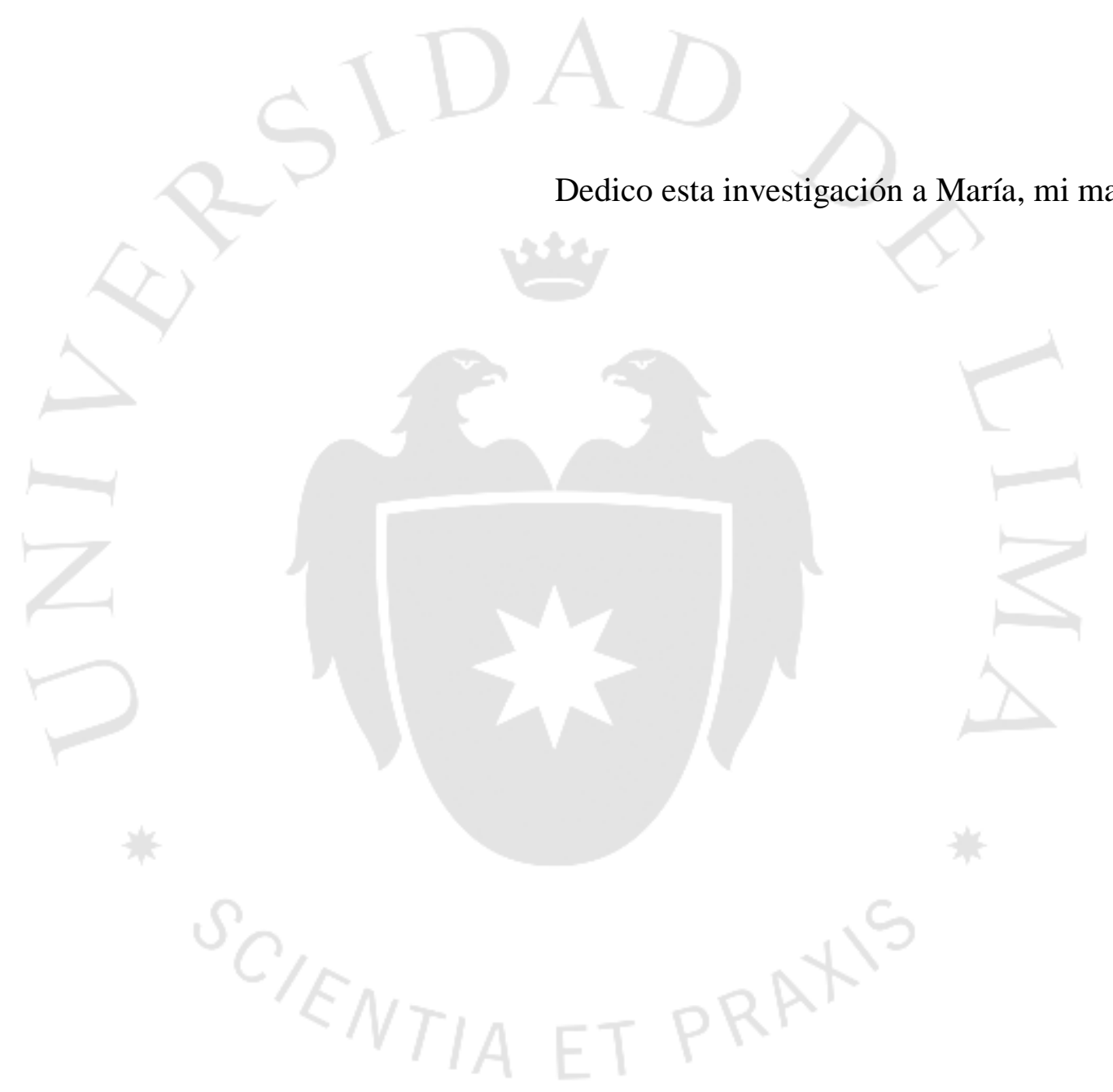




\section{TABLA DE CONTENIDO}

INTRODUCCIÓN

CAPÍTULO I: EL SISTEMA REGISTRAL PERUANO ................................4

1.1. Concepto y características del Sistema .................................................6

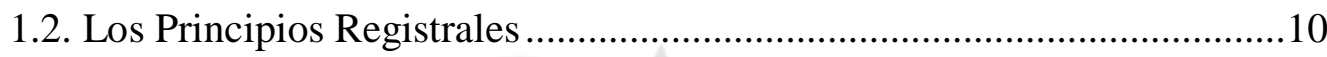

1.3. El Registro Mercantil y los terceros .......................................................13

1.4. La teoría de la apariencia y los terceros registrales .................................17

CAPÍTULO II: EL TERCERO DE OPONIBILIDAD MERCANTIL ..............22

2.1. La Oponibilidad Registral: fundamento y características ........................25

2.2. El Tercero Registral Mercantil de Inoponibilidad.................................28

CAPÍTULO III: EL TERCERO DE FE PÚBLICA REGISTRAL MERCANTIL

3.1. Fundamento de la Fe Pública Registral .....................................................36

3.2. La Fe Pública Registral del Código Civil y el Tercero .............................40

3.3. El Tercero Mercantil de Fe Pública Registral .........................................43

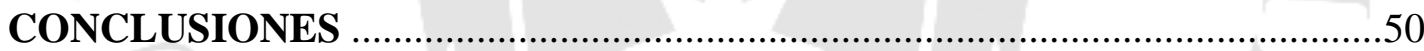

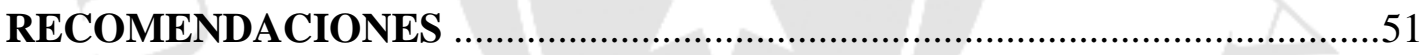

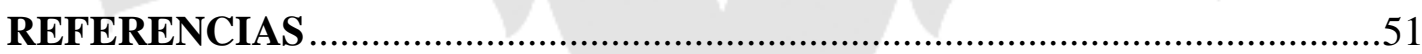

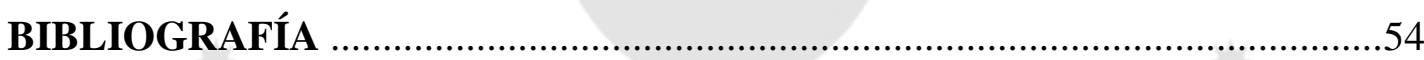




\section{INTRODUCCIÓN}

La presente investigación versa sobre los terceros registrales que existen a nivel del Registro Mercantil en el Perú.

Conforme es sabido, en la doctrina se concibe la figura del "tercero registral", quien en buena cuenta es un personaje al cual el ordenamiento jurídico provee de protección o perjudica, según las diversas situaciones jurídicas que se producen en los registros públicos.

A su turno, en la doctrina registral, existen diversas clasificaciones de los terceros registrales, las cuales son generalmente desconocidas, no sólo en cuanto a su naturaleza, sino también en cuanto a las características que deben revestir para ser tales y para merecer -por ende- protección.

Por ello, este trabajo da cuenta en primer término de la necesaria distinción entre los registros de bienes y los registros de personas (en particular, las personas jurídicas), donde queda claro que las normas y Principios Registrales que informan a cada uno de ellos son distintos, en atención al objeto materia de publicidad y a la función de cada uno de estos registros.

Siendo así, hemos dividido el presente trabajo en tres partes: Una primera en la que se analizan conceptos generales vinculados a los registros públicos, de entre los cuales resalta la revisión del rol de los Principios Registrales en el ordenamiento jurídico y se analiza las diferencias existentes entre los registros de bienes y de personas. Asimismo, se analiza la naturaleza, objeto y función del Registro Mercantil, a fin de establecer cómo coadyuva esta herramienta estatal a brindar seguridad en el tráfico jurídico - económico. Finalmente, en esta primera parte, se da cuenta del rol de la Teoría de la Apariencia, su presencia en el ordenamiento jurídico y particularmente en el ordenamiento mercantil societario; se apunta además a desarrollar a grandes rasgos una Teoría General de la Apariencia Jurídica, como base para la protección de los terceros registrales que tienen presencia en el Registro Mercantil y que se estudian en la segunda y tercera parte del trabajo. 
En la segunda parte o capítulo, se desarrolla y analiza el Principio de Oponibilidad Registral, el cual supone el respeto por parte de todos los ciudadanos de las situaciones que publicita el Registro; sin embargo, hay ocasiones en que se omite inscribir situaciones jurídicas con visos de oponibilidad, con lo cual hablamos de la inoponibilidad registral y sus consecuencias.

De igual manera, se analiza las normas del Código de Comercio, Ley General de Sociedades y Registro Mercantil que regulan el principio en cuestión, estableciendo finalmente las características que consideramos debe reunir el llamado por nosotros "Tercero Registral Mercantil de Oponibilidad" para merecer protección -aunque relativapor el ordenamiento jurídico.

Finalmente, la tercera parte o capítulo de este trabajo, analiza y desarrolla el Principio de Fe Pública Registral y su presencia en el Perú, la cual defitivamente viene dada por el artículo $2014^{\circ}$ del código civil; sin embargo, se plantea la problemática que surge a propósito de la norma que aprueba este principio para el Registro Mercantil y se discute su aplicabilidad en el ordenamiento jurídico peruano. Es importante destacar que a pesar de la posición que adoptamos con respecto a mantener o no al llamado por nosotros “Tercero Mercantil de Fe Pública Registral” dentro del concierto normativo que informa al Registro Mercantil, estamos proponiendo en el presente cuáles serían las características que debiera ostentar este personaje en el momento en que se regule adecuadamente, lo cual consideramos modestamente podría ser tenido en cuenta por el legislador como presupuestos de aplicación del Principio de Fe Pública Registral.

Nuestra modesta contribución, en suma, va por delimitar las características y presupuestos que todos los operadores jurídicos, en particular los jueces, deben tener en cuenta cuando se trata de brindar protección jurídica a aquellos terceros que se vinculan con las sociedades. 


\section{CAPÍTULO I: EL SISTEMA REGISTRAL PERUANO}

Es frecuente que los operadores jurídicos en nuestro país aludan a los "registros públicos", como aquella institución del Estado destinada a cobijar sus documentos continentes de determinados actos, hechos, derechos o situaciones jurídicas. Efectivamente, la Ley No 26366 (1995) que crea el Sistema Nacional de los Registros Públicos, indica en su artículo $10^{\circ}$ que la SUNARP (ente rector de dicho sistema) es un “organismo descentralizado autónomo del Sector Justicia y ente rector del Sistema Nacional de Registros Públicos, con personería jurídica de Derecho Público”.

Siendo así, una primera forma de aludir a los registros públicos (hoy día SUNARP) es en su calidad de ente estatal, es decir, como parte de la llamada administración pública y regido por tanto de manera primigenia por la Ley No 27444 Ley del Procedimiento Administrativo General para todo aquello referido a los procedimientos de orden general administrativo que se siguen ante ella.

La segunda acepción que adquiere la referencia a los "registros públicos", importa aludir a una herramienta que permite irradiar importantes efectos jurídicos hacia terceros, debiendo entenderse que dicha noción de tercero, de modo básico alude a aquél ajeno al negocio jurídico -en el cual por principio hay dos partes involucradas-. Nótese de entrada que, el registro como tal, nada añade a la relación jurídica existente entre las partes que la conforman, pues ambas deben cumplir las obligaciones y sus correspondientes prestaciones; de lo que se trata es de romper con el principio de relatividad de los contratos regulado en el artículo $1363^{\circ}$ del código civil peruano, el cual reza que "los contratos sólo producen efectos entre las partes que los otorgan y sus herederos...", llevando entonces las consecuencias jurídicas del negocio hacia terceros que deben de alguna manera someterse a lo registrado, sea para utilizarlo en su favor, sea para soportarlo.

Tal vez resulte interesante decir, para un cabal entendimiento, que la denominación "registros públicos" se origina en el hecho de que en estricto, la Sunarp contiene "bases de datos" formadas por su registro generalmente voluntario, y que por 
otro lado, el acceso a dichas bases de datos es libre para todos; en esa medida, la inscripción de la compraventa de una casa o del aumento de capital de una empresa determinada, se registra en las bases de datos correspondientes de la Sunarp y cualquier persona puede acceder a dicha información. Más aún, a propósito de dar cuenta de los antecedentes del registro en el derecho germánico, García García (como se citó en Arias Schreiber Pezet, 2006) precisa que:

En un principio (siglo VII) existe la costumbre de redactar los negocios en libros registrales por parte de iglesias y monasterios, donde se han encontrado libros y documentos relativos a transmisiones inmobiliarias. En el siglo X son los señores feudales los que usan esa costumbre respecto a sus propiedades. Ahora bien, cuando surge el antecedente de Registro es cuando el libro y sus asientos se redactan y conservan por un Tribunal o por el Concejo de la ciudad. Entonces se pasa de los libros meramente particulares a los libros oficiales, a los registros públicos. (p.785)

Ahora bien, si como hemos mencionado, cualquier persona puede conocer el contenido de los registros públicos, es justamente esa posibilidad de conocer la que afecta a quien desde fuera (llamémosle por ahora simplemente "el tercero") ha tomado noticia del acto, hecho o derecho inscrito.

En rigor, nadie podrá conocer efectivamente el contenido integral de todo lo que está inscrito en el registro, pues de por sí la empresa resulta tan infructuosa como imposible, pero sí le es posible definitivamente conocer aquello que le interesa pues es público, y por tanto le repercute. A modo de ejemplo, piénsese en quien desea conocer si una persona es representante de otra y si su poder está vigente: pues en ese caso, bastará revisar la partida registral del registro de mandatos y poderes y el título archivado que corresponda para contratar con seguridad jurídica. Dicha persona empero, podría omitir revisar el contenido del registro, por lo cual, si el poder ya estaba revocado e inscrita dicha revocatoria, el tercero no podrá ampararse arguyendo que no acudió al registro, pues la ley presume iure et de iure que todos conocen el contenido del Registro.

Ese es uno de los pilares que justifica la existencia de los registros: la llamada cognoscibilidad general, esto es, la posibilidad de conocer, aunque efectivamente no se haya conocido. De tal guisa que, el sistema jurídico del cual forma parte el registro, introduce a este último como un mecanismo de publicidad de actos, hechos, derechos y/o 
situaciones jurídicas, los cuales una vez inscritos no pueden pasar por desconocidos a nadie, o si se quiere, pasa por conocido por todos sin excepción, lo que genera mayor certeza en el tráfico jurídico en general. Conforme señala Rojo (2004): "la cognoscibilidad, es decir, la mera posibilidad de conocer, equivale al conocimiento.” (p. 103)

Ahora bien, siendo los registros públicos una herramienta jurídica que produce efectos sustantivos en terceros, requiere sin duda de una organización normativa que tienda a la eficacia en sus objetivos, por lo cual podemos hablar de un Sistema Registral Peruano, bajo la premisa de que un sistema es un "conjunto de principios, normas o reglas, lógicamente entrelazados entre sí, acerca de una ciencia o materia.” (Cabanellas, 1989, p. 449)

\subsection{Concepto y características del Sistema}

Conforme sentencia Alfonso de Cossio (como se citó en Arias Schreiber Pezet, 2006), un sistema hipotecario, y para nosotros un sistema registral en general:

No es otra cosa que el conjunto armónico de principios que aspira a producir mediante la institución del Registro de la Propiedad, la necesaria seguridad al tráfico de los bienes inmuebles y a la constitución de relaciones reales sobre los mismos, ofreciendo con ello sólidas bases en qué asentar el crédito hipotecario. (p. 828)

Valga primeramente la aclaración en el sentido de que en España se llama Derecho Hipotecario a la rama jurídica que nosotros denominamos Derecho Registral, estando la explicación en que -acaso- el primer derecho para cuya inscripción y publicitación nació el Registro como herramienta jurídica de oponibilidad, es para el derecho real de hipoteca, dando fin a una era de gravámenes ocultos o hipotecas clandestinas propias del antiguo régimen. $\mathrm{Y}$ es que ciertamente, era factible y de suyo inseguro adquirir la

\footnotetext{
Debe quedar bien diferenciado lo que es el Sistema Nacional de los Registros Públicos, que como hemos mencionado ha sido creado por la Ley $N^{\circ} 26366$ y debe entenderse como aquel andamiaje orgánico existente en el país como parte de la Administración Pública (organización de la SUNARP y sus zonas y oficinas registrales), del Sistema Registral Peruano, entendido éste como ese conjunto de principios y normas jurídicas que regulan los requisitos y efectos de las inscripciones en los registros públicos (Principio de Fe Pública Registral, Legitimación, entre otros).
} 
propiedad de un solar y descubrir con posterioridad a la adquisición del dominio que el predio soportaba una hipoteca -no inscrita-; he ahí el motivo remoto por el cual se crean los registros públicos llamados en ese entonces Oficio de Hipotecas, y también he ahí la razón por la cual el derecho real de hipoteca, a diferencia de otros derechos como la propia garantía mobiliaria de hoy, es un derecho constitutivo, es decir, que recién se configura o constituye con la inscripción registral. Mucho después se establecen como actos inscribibles el derecho de propiedad y mucho más luego, el acceso de actos de comercio a un registro jurídico.

En segundo término, es importante también aclarar que en el caso español, sin duda por su mayor antigüedad, es común encontrar alusiones al Registro de la Propiedad para definir o hacer llamamiento de conceptos "generalmente" aplicables a todos los registros, cual si se tratara del único registro existente. Así lo advertimos en la cita de De Cossio, quien al aludir a los principios (hipotecarios o registrales) lo hace con referencia al registro de la propiedad, cuando en realidad, en todos los registros, como por ejemplo en el registro mercantil, existen principios que caracterizan al sistema registral en dicho ámbito y perfilan los efectos jurídicos que dichos principios plantean.

Así entonces, podemos decir que el Sistema Registral Peruano es aquél conformado por determinados Principios Registrales que le caracterizan y que definen determinados efectos jurídicos sustantivos hacia los terceros, alcanzando con dicha caracterización diferenciarse justamente de otros sistemas registrales.

Previo a definir las características del sistema registral peruano, es importante dejar sentado cómo funcionan todos los sistemas registrales del mundo o qué tienen en común: En palabras cortas, podemos decir que cualquier sistema registral tiene como objetivo dar publicidad jurídica a los actos, hechos o derechos que se inscriben en sus registros (bases de datos), generando con dicha publicidad efectos sustantivos hacia terceros (a.e. oponibilidad de lo inscrito, legitimación registral, fe pública registral).

Conforme a lo dicho, la nota común en todos los sistemas registrales es la publicidad de lo inscrito, a través de la cognoscibilidad primero y luego, en base al acceso real del contenido de tales inscripciones. Lo que los diferencia son aspectos tales como la obligatoriedad en la inscripción, el carácter marcadamente declarativo o constitutivo de las inscripciones, la causalidad que sustenta a los asientos del registro, entre otros que veremos seguidamente como notas caracterizadoras del sistema registral peruano. 
De la lectura de los clásicos del derecho hipotecario (registral) español, se advierte la tendencia generalizada a dar cuenta del estudio comparatista de diversos sistemas registrales, entre los cuales se cuentan por principio el sistema registral alemán, el francés, el australiano, el italiano y el español.

Cuando se atiende a las características de cada uno de dichos sistemas, se advierte efectivamente que entre ellos hay diferencias sustanciales; así, en algunos de ellos hay eficacia constitutiva de las inscripciones, a diferencia de otros; en algunos la inscripción es obligatoria; en otros, se carece de asientos resumen como en el caso peruano y en algunos otros, la inscripción es convalidante, o lo que es lo mismo, la inscripción sanea el título inválido o viciado.

Como no es éste el espacio para revisar las características de cada uno de estos sistemas, nos limitaremos a dar cuenta de las que ostenta el sistema registral peruano, lo cual constribuirá a entender de mejor manera la descripción de los terceros registrales regulados en el reglamento del registro mercantil a cargo de la Sunarp. En este punto, tomamos como referencia a Arias Schreiber Pezet (2006), sin embargo, no acogemos íntegramente su postulado, pues el mismo apunta a las carácterísticas del registro en materia de predios, antes que a las características del sistema en pleno. Veamos entonces lo que para nosotros son las carácterísticas del sistema registral peruano²:

a) Es un sistema de oponibilidad/inoponibilidad, donde lo inscrito se opone a lo no inscrito; y viceversa, donde lo no inscrito, es inoponible a lo inscrito.

b) Es un sistema de legitimación de lo inscrito, en virtud a lo cual, se presume iuris tantum que los asientos son válidos y exactos y por tanto gozan de eficacia, en tanto no aparezca del propio registro lo contrario.

c) Es un sistema de fe pública registral, en el cual se protege de manera absoluta a quien de buena fe adquiere un derecho bajo determinadas circunstancias y requisitos.

d) Es un sistema no convalidante, es decir que la inscripción no sanea el título viciado por el hecho de acceder al registro; en consecuencia, todos los actos,

2 Debe quedar claro que cada una de las características del sistema registral que se detallan, admiten matices o excepciones. 
hechos, derechos o situaciones jurídicas inscritas, son pasibles de ser declarados nulos.

e) Es un sistema causal (o no abstracto), en virtud al cual las mutaciones en las partidas registrales se producen en virtud a la inscripción y consecuente calificación de un determinado acto jurídico -causa-, y no en razón a la sola manifestación de voluntad -abstracta- del titular inscrito para que opere la mutación en la partida registral sin aludir al acto.

f) Es un sistema de inscripción mayoritariamente declarativa (o no constitutiva), donde el derecho a inscribirse se constituye o configura fuera del registro; siendo así, la inscripción tiene básicamente efectos publicitarios dirigido a los terceros.

Aun cuando pareciera a la luz de lo dicho en este epígrafe, que el registro se limita a proclamar o publicitar el derecho que ya se constituyó o nació fuera de sus libros, vale la pena mencionar que J.M. García García nos habla del principio de inscripción, la cual "se convierte por esa razón en conformadora, configuradora o cuasiconstitutiva de la eficacia real erga omnes del derecho real". (Pau Pedrón, 2001, p.175)

Conforme rescata Pau Pedrón (2001):

La importancia de esta aportación a la teoría de los principios hipotecarios es grande; no sólo porque pone de relieve el efecto más general e inmediato de las inscripciones, son porque deshace uno de los errores más extendidos en el ámbito hipotecario: que la llamada "inscripción declarativa" $-o$ incluso "meramente declarativa"- "no añade un valor especial por sí misma" (en frase de Sanz que recoje J.M. García), o que implica una simple "rectificación del contenido inexacto del Registro, porque la modificación jurídico-real ya ha surgido antes" (Roca, citado por el mismo autor). En realidad sucede todo lo conrario: al [sic] Registro añade un decisivo valor al derecho real: su plena oponibilidad; podría decirse incluso -invirtiendo la afirmación de Roca-, que la inscripción rectifica la constitución del derecho real: de tener sólo efectos limitados, le dota de efectos absolutos. (p.176) 
g) Es un sistema de inscripción facultativa, por lo cual no existe generalmente obligatoriedad de inscribir; sucede simplemente que al no producirse la inscripción, no se activan los efectos jurídicos propios del sistema. (p.840)

\subsection{Los Principios Registrales}

Conforme señala Gonzales Loli (2010):

Los principios son reglas, enunciados o máximas que orientan la conducta y en el ámbito del Derecho, orientan la aplicación de las normas y su interpretación, por lo tanto aun cuando no sean calificadas expresamente como normas, forman parte del ordenamiento jurídico y los encontramos en todas las materias jurídicas, como lo es en el Derecho Registral. (p.231)

Los principios registrales por su parte, son los pilares o las bases que sustentan y fundamentan cada sistema registral; cuando hemos hecho referencia a los diversos sistemas registrales existentes, cada uno de ellos ostenta distintos principios (algunos coincidentes) los cuales justamente cuando entran en juego en sus respectivos ordenamientos jurídicos, definen determinadas respuestas a los problemas que la sociedad les plantea.

En el derecho hipotecario (sistema registral español) la conceptualización y definición de la naturaleza jurídica, así como el establecimiento de la función de los principios registrales, cobra relevancia y exacto dimensionamiento acaso recién con el insigne hipotecarista don Jerónimo Gonzales, a quien se reconoce cierta paternidad en la materia, a pesar de los pronunciamientos anteriores a él sobre el particular; sin embargo, la claridad en la visión del insigne hipotecarista establece el camino a seguir en la interpretación y aplicación de los principios registrales.

Para el caso peruano, resulta altamente didáctica la fórmula que propone Álvaro Delgado (como se citó en Arias Schreiber Pezet, 2006), para conceptualizar los principios aludidos con plena aplicabilidad a cualquier sistema registra y por tanto también al sistema registral peruano:

Los principios registrales son las características o rasgos fundamentales que informan a un determinado sistema registral y que lo distinguen o asemejan de otros. Pero también son los medios o instrumentos a través de los cuales, en forma 
mediata o inmediata, se alcanzan los fines de la publicidad jurídica registral... Por tanto, los principios registrales, en tanto características o rasgos fundamentales que dan forma sustancial a un determinado sistema, no son otra cosa sino las diversas maneras como este sistema de publicidad registral en particular cumple sus fines de seguridad jurídica. (p. 825)

Antes de señalar cuáles son los principios que conforman el sistema registral peruano, habrá que mencionar que la doctrina reconoce que existen principios acogidos en texto positivos, otros no recogidos en textos positivos y algunos contrarios a los recogidos en textos positivos (Pau Pedrón, 2001, pp. 177-178), dando lugar incluso a los llamados principios apócrifos, es decir "principios ciertos pero humildes, que se limitaban [a] destacar rasgos menores del sistema." (Pau Pedrón, pp.166-167). En este trabajo, nos vamos a limitar a analizar los principios acogidos en determinadas normas positivas y de entre estos, los principios de oponibilidad y fe pública registral en el registro mercantil.

Al decir de Casado Urbano (2002), los principios registrales:

Informan todo el sistema registral de que se trate; los principios, respecto a los libros y archivos registrales son, con permiso de Santo Tomás, algo así como el alma al cuerpo. Por ello no resulta siempre fácil aprehenderlos, definirlos y enumerarlos. (p. 17)

Esta es una de las razones por las cuales se justifica la presente investigación, y es que como hemos mencionado líneas atrás, algunos de los principios registrales se leen e interpretan y han sido diseñados para aplicarse en el los registros de bienes (particularmente pensados para el Registro de la Propiedad Inmueble) y por tanto, es necesario establecer a cabalidad como se deben interpretar y aplicar algunos de estos principios en el registro mercantil que tiene una naturaleza distinta y que tiene correlato con el Derecho Societario, cuya naturaleza y fines definitivamente es distinta al Derecho Civil y particularmente al derecho de propiedad.

Es además necesario establecer el verdadero alcance de los principios registrales aplicables en el registro mercantil, pues:

Dentro de esa función de "orientar" la aplicación del Derecho hipotecario [registral], los principios tienen tres cometidos concretos: a) Facilitar la interpretación de las normas registrales, porque en la duda, la interpretación ha de 
hacerse "secundum principia" y nunca "contra principia"; b) Permitir la integración del Ordenamiento jurídico registral, y concretamente por la vía de la “analogía iuris"; ... y, c) Y cumplen los principios hipotecarios [registrales] una tercera función -que ha puesto de relieve Lacruz-: acotar el marco dentro del cual ha de actuar el redactor de los textos legales y reglamentarios. Aunque, a mi juicio, esta función ha de circunscribirse a los que he llamado principios hipotecarios esenciales o inmanentes: ellos son los únicos que proceden de la naturaleza de la institución, y contrariarlos sería, por eso mismo, desnaturalizar la institución. (Pau Pedrón, 2001, p.183)

En cuanto al caso peruano, es en el Libro IX del código civil, referido a los Registros Públicos, donde se recogen de manera expresa los principios registrales aplicables a todos los registros; basta dar lectura a los artículos $2010^{\circ}$ al $2017^{\circ}$ de dicho cuerpo normativo. Sin embargo, conforme puede apreciarse, en el caso de Principio de Tracto Sucesivo regulado en el artículo $2015^{\circ}$ y el Principio de Fe Pública Registral regulado en el artículo $2014^{\circ}$, ambos obedecen en su diseño a la dinámica del Registro de Propiedad, resultando de difícil o nula aplicación en el registro mercantil.

Ciertamente los demás principios regulados en el código civil $\left(2010^{\circ}, 2011^{\circ}\right.$, $2012^{\circ}, 2013^{\circ}, 2016^{\circ}$ y $2017^{\circ}$ ) sí son plenamente aplicables a todos los registros integrantes del Sistema Nacional de los Registros Públicos que lleva la SUNARP.

De otro lado hay que mencionar que "por su parte, el Código de Comercio regula también los efectos de las inscripciones societarias en sus artículos $17^{\circ}, 18^{\circ}, 24^{\circ}, 26^{\circ}$ y $29^{\circ}$, pero sin establecer "expresamente" la existencia de principios registrales especiales aplicables al denominado Registro Mercantil” (Gonzales Loli, 2010, p. 231).

Finalmente en cuanto a los principios registrales aplicables al Registro Mercantil, hay que mencionar que en un afán de adaptación, la SUNARP al dictar su Reglamento del Registro de Sociedades mediante Resolución SUNARP N²00-2001/SN, reguló de manera particular el Principio de Especialidad, el de Fe Pública Registral, el de Tracto Sucesivo y el de Autenticación, sin perjuicio de la aplicación en el citado registro mercantil de los demás principios regulados en el código civil y en el TUO del Reglamento General de los Registros Públicos. 
Vale por el momento mencionar -con cargo a realizar el análisis pertinente más adelante-, que la regulación y adaptación del Principio de Fe Pública Registral al Registro Mercantil en el artículo IV del título preliminar del Reglamento, ha sido certeramente criticado, toda vez que:

El Reglamento no puede modificar ni alterar el régimen sustantivo de nulidades, efectos y excepciones que se señalan en las leyes; por tal razón, la única forma de interpretar correctamente el artículo IV TP-RRS es considerar que esta norma simplemente reitera el principio de fe pública para los casos en que la ley lo permite, y no más allá; por tanto, la disposición reglamentaria es una redundancia -y no puede ser de otra manera- de los artículos $148^{\circ}, 366^{\circ}$ y 390 LGS (Gonzales Barrón, 2013, p. 141).

Otro autor sostiene más bien, que "dada la importancia y utilidad de los principios registrales en el ámbito societario, tranquilamente podemos referirnos a ellos como Principios Registrales Societarios" (Gonzales Loli, 2010, p.231).

\subsection{El Registro Mercantil y los terceros}

Existe unanimidad en la doctrina en referir los antecedentes del Registro Mercantil, el cual

Tuvo su origen en la Edad Media en la Matrícula de Comerciantes que llevaba cada Consulado. Su evolución histórica desde la perspectiva de la publicidad registral legal permite distinguir tres grandes etapas (MENENDEZ). $1^{\mathrm{a}}$ ) la etapa corporativa, de origen del Registro en el seno de los Consulados de Mercaderes; $2^{\text {a }) ~ l a ~ e t a p a ~ n e g o c i a l, ~ c a r a c t e r i z a d a ~ p o r q u e ~ e l ~ l e g i s l a d o r ~ c o n d i c i o n o ́ ~ l a ~ v a l i d e z ~ d e ~}$ los contratos inscribibles a su inscripción (Cdeco. francés de 1807 y español de 1829); y, $3^{\text {a }}$ ) la etapa propiamente registral, en que generalmente la inscripción no es requisito de validez, sino de oponibilidad a los terceros, así como que éstos pueden confiar en la apariencia de los asientos registrales. (Vicent Chuliá, 2006, p. 143)

En cuanto a lo dicho, es menester mencionar que resulta frecuente la idea, por demás errada, de que el registro mercantil es un registro de inscripción constitutiva, es decir, que los actos inscribibles en este registro deben registrarse para su debida configuración o existencia; esta característica es excepcional toda vez que, al igual que 
en la mayoría de registros jurídicos a cargo de la Sunarp, la inscripción es declarativa, es decir, los hechos y derechos se constituyen y por tanto son eficaces desde fuera del Registro, y mas bien acceden a este último para diversos fines, entre los cuales se cuenta como el principal la oponibilidad a los terceros.

Sabido es por su parte que, de los pocos casos en que el Registro Mercantil recoge la inscripción constitutiva, es cuando se trata del nacimiento de la sociedad con la subsecuente adquisición de personería jurídica.

Fuera del caso de la adquisición de personería, la ley no señala en forma explícita otra hipótesis de inscripción constitutiva. Por tal motivo, existen algunos supuestos que generan dudas. Así, en el caso de la fusión por constitución de una nueva sociedad, resulta evidente que la inscripción tiene caràcter constitutivo... Igual reflexión genera la escisión de sociedades, pues el artículo 378 LGS prescribe que la escisión está supeditada a la inscripción... En el caso de la transformación de sociedades, una interpretación lógica del artículo 341 LGS debe llevar a sostener que la inscripción tiene eficacia constitutiva. (Gonzales Barrón, 2013, p. 88-89)

Esto es importante de tener en cuenta básicamente por dos razones:

a) La primera es para que no exista duda en los operadores jurídicos sobre el exacto momento en que el hecho jurídico surge y por tanto, desde qué momento despliega sus efectos jurídicos. Piénsese por ejemplo, en el caso de un asiento registral que refleje el otorgamiento de poder a una persona en virtud a un acuerdo adoptado en determinada fecha, habiéndose certificado notarialmente la firma del gerente general en una fecha posterior, registrandose como es obvio dicho acuerdo en una fecha distinta de la primera y de la segunda. La pregunta sería ¿desde cuándo ostenta poderes la persona para ejercitar las facultades otorgadas? La respuesta es, que desde la primera fecha; es decir, desde que sesionó el órgano dador de facultades al representante. Ello es así, porque la inscripción de los poderes es facultativa; pero si la inscripción de los poderes fuera constitutiva por mandato de la ley, la respuesta sería la tercera fecha, es decir, aquella relativa al asiento de presentación del título al registro; $y$, 
b) Porque no siendo obligatoria de manera ordinaria la inscripción en el Perú, debe quedar claro la utilidad de inscribir un acto declarativo en el Registro. (Con respecto a los actos constitutivos no cabe duda pues la inscripción dota de vida y existencia al acto).

Este último punto nos lleva a preguntarnos si el Registro Mercantil es una herramienta que favorece o perjudica a los comerciantes, o a los terceros. Esta inquietud, en principio, cobra relevancia en tanto si la registración de los actos favorece a los comerciantes, éstos deberán observar riguroso celo en pretender inscribir todos los actos que admita el ordenamiento, que en el caso peruano se rige por el principio de numerus clausus, o si mas bien, los terceros que contratan con las sociedades deben indagar rigurosamente en los asientos del registro, tomando por la realidad básicamente lo que está allí publicitado.

De los Ríos Sánchez (2014) llama la atención sobre el hecho de que:

La publicidad legal no debe contemplarse, exclusivamente, como una "pieza” más del estatuto jurídico del empresario, sino más bien como una institución que permite la transparencia del mercado. No está pensada, al menos no primordialmente, para defender al comerciante, sino para hacer públicos datos relevantes de su actividad, y que los terceros puedan actuar conforme a los mismos. (pp. 219-220)

Así también, Rojo (2004) señala que “el Registro mercantil es una institución escencialmente dirigida a los terceros" (p. 104).

Empero otros autores prefieren acentuar la utilidad en el comerciante, tomando como el sentido y fin de la publicidad registral "Para que los propios empresarios puedan ampararse en los efectos jurídicos de la publicidad frente a los terceros que pretendieran ignorar o desconocer las consecuencias de los actos publicados” (Uría, 1987, p. 103).

Finalmente entendemos que se trata de dos caras de la misma moneda; así, Garrigues (1984) nos enseña que:

Reconocidos en el Derecho Moderno los aspectos, positivo y negativo, de la publicidad material del Registro, resulta ociosa la cuestión de si el R.m. favorece al comerciante o al tercero. En realidad, la inscripción favorece al comerciante y perjudica al tercero (efectos positivos) y la no inscripción favorece al tercero y perjudica al comerciante (efectos negativos). Se trata de dos facetas de un mismo 
principio de publicidad. Lo que ocurre es que las consecuencias prácticas de este mismo principio son más favorables al comerciante que al público en general. (p. 702)

El maestro español parece referirse a que la inscripción coadyuva contundentemente a delimitar el ámbito de responsabilidad del comerciante, y por tanto, bajo tal premisa, éste sería el más favorecido. Consideramos al respecto que este es uno de los aspectos a tener en cuenta al momento de establecer la finalidad de la inscripción en el registro mercantil, pero no el único. Existen otros actos que merecen acogida registral y que tienen que ver con el tráfico jurídico, o con la existencia y la organización del comerciante; por tanto, consideramos, el registro mercantil sirva para ambos. "El Registro Mercantil es aquel Registro público que tiene por objeto la publicidad de los empresarios, de las sociedades mercantiles y demás sujetos inscribibles, así como de determinados hechos y actos relativosa esos sujetos (Rojo, 2004, p. 104).

Finalmente, es el legislador quien ha establecido cuáles actos merecen inscribirse y cuáles no. Basta dar lectura al Reglamento del Registro de Sociedades aprobado mediante Resolución $N^{\circ}$ 200-2001-SUNARP/SN que sin duda es una buena norma en general, pues como todo reglamento de inscripciones, cumple con su función de aclarar aquellos aspectos importantes para lograr la inscripción de actos previstos en la Ley, pero que esta última omite indicar.

Es importante mencionar que esta norma tiene su basamento en el Código de Comercio de 1902, el cual contiene algunos pocos artículo vigentes y de entre ellos, algunos referidos al Registro Mercantil y a los principios registrales que inspiran y caracterizan a dicho registro. El código, en efecto, alude en su Sección II al Registro Mercantil, el cual varía de denominación a Registro Societario cuando entra en vigor la Ley N 26366 - Ley de creación de la Sunarp- y lo califica como Registro Societario.

Sin embargo, hay que mencionar que esta norma es aprobada por una resolución administrativa y por tanto, debe ser el correlato de lo previsto expresamente en la ley. No podría aceptarse por ello que el Reglamento establezca consecuencias jurídicas más allá de las previstas en el Código o en otra norma con rango de ley.

Cuando tratemos del Tercero de Oponibilidad veremos que hay cierto correlato entre lo previsto en el Reglamento del Registro Societario y el Código de Comercio, a 
diferencia de lo que ocurre en el caso del Tercero de Fe Pública Registral, caso en el cual el reglamento ha regulado la fe pública registral para el derecho societario.

\subsection{La teoría de la apariencia y los terceros registrales}

Como parte de esta investigación y teniendo en cuenta la evidente acogida y manifestación que se produce en el registro mercantil, nos parece conveniente dar algunas luces sobre la llamada "Teoría de la Apariencia” y su aplicación en el Perú.

Definitivamente dicha doctrina tiene presencia a través de diversas normas en el derecho peruano, no sólo en el campo del derecho civil, sino también en el societario, en el derecho cartular y en el derecho del consumidor, entre otros, y tiene como objeto dispensar protección al tercero (aquél ajeno por principio al acto, hecho o negocio) que confía en lo que se presenta como realidad, aunque es sólo aparente. Esta doctrina que viene de antiguo parte del hecho de que:

El ordenamiento jurídico no es un mero resultado de la lógica. Sus conceptos y reglas son medios para la mejor reglamentación de las relaciones de la vida y del tráfico. En el tráfico no es siempre posible al individuo el investigar en la esencia de las cosas, debiendo atenerse normalmente a su apariencia externa y confiar en ella. La seguridad del tráfico quedaría muy perjudicada si esta confianza no encontrase protección... la cuestión reside en saber en qué medida ha de protegerse la confianza en estos supuestos de hecho externos. (Lehmann, s. f., p. 203)

Privilegiar la llamada seguridad del tráfico en desmedro de la seguridad estática tiene sus detractores, pues argumentan no sin razón, que es altamente injusto preferir a un actor frente al otro, cuando este último no realizó ningún comportamiento que le haga soportar la solución desfavorable que le dispensa el ordenamiento jurídico. Piénsese en el caso aquél que retrata el artículo $2014^{\circ}$ del código civil (incluso en la venta de un predio por quien lo adquirió mediante un ilícito penal), en el cual se prefiere al adquirente del bien a pesar que adquirió de quien no es el verdadero propietario.

Sin embargo, en el caso del derecho societario y del registro mercantil la discusión es menos ardua pues en este ámbito, depende únicamente de la sociedad desvirtuar lo aparente y mostrar la realidad, a través de la publicidad del registro cuando corresponda. 
Siendo así, habrá que privilegiar la protección al tercero que confía, antes que a la sociedad mercantil que pudo a su sola voluntad destruir dicha confianza, sufriendo esta última las consecuencias de su inacción.

Es por ello que Falzea (2006) sentencia que:

En los tiempos modernos, la exigencia de hacer más ágiles las distintas formas de circulación jurídica de los bienes, ocasionada por la expansión del comercio y de los tráficos, así como por la intensificación del ritmo de las relaciones económicas, ha impuesto una protección reforzada de los terceros y, en sentido contrario, una menor garantía de los derechos preexistentes y de las situaciones jurídicas preconstituidas. $\left(\right.$ p.177) ${ }^{3}$

Como hemos mencionado, en realidad la teoría de la apariencia se esconde tras diversas normas del derecho nacional, sin embargo, aunque no muy profusa, existe alguna jurisprudencia que recoge esta teoría y acoge la protección al tercero. Se trata del caso en que el cliente de un conocido restaurante, estaciona su auto en un terreno contiguo al local en el cual figura un letrero con el nombre de dicho establecimiento. Al salir del local, el cliente encuentra que su auto había sufrido algunos desmedros y al reclamar al restaurante, éste aduce que antes alquilaba dicho terreno para estacionamiento de sus clientes, mas dicho contrato habíase extinguido. Ante el reclamo del cliente (consumidor), la Sala correspondiente del Indecopi emitió la (Resolución Final N ${ }^{\circ} 240$ 2002- CPC) del 10 de abril de 2002, que a la letra indicó que en este caso:

Se ha configurado un supuesto de apariencia, que es una situación compleja, en la cual una situación real se manifiesta o significa frente a los terceros de otra manera, vale decir, a través de una situación aparente. Este supuesto de apariencia se manifiesta objetivamente, bajo criterios socialmente apreciables. Frente a ello, el ordenamiento jurídico considera eficaz la situación aparente, privilegiándola frente a la situación real, a efectos de proteger a los terceros que, confiando en la misma, han celebrado actos

\footnotetext{
Recomendamos con énfasis la lectura del opúsculo de Angelo Falzea: "El Principio Jurídico de la Apariencia”, publicado en el Perú en la Revista de Derecho No 59 de la PUCP. Título original: «Apparenza». En FALZEA, Angelo. Ricerche di teoria generale del diritto e di dogmatica giuridica, II, Dogmatica giuridica. Milán: Giuffrè, 1997, pp. 809-856. Traducción, autorizada por el autor, de León L. Leysser.
} 
jurídicos. Las situaciones de apariencia no son ajenas a las previsiones del Código Civil. Así, se regula al acreedor aparente (artículo $1225^{\circ}$ c.c.), al heredero aparente (artículo $665^{\circ}$ c.c.), entre otros. En estos casos, los actos realizados tanto con el acreedor aparente, como con el heredero aparente, tienen efectos jurídicos. En efecto, en el primero, se extingue la obligación por el pago hecho al acreedor aparente y, en el segundo, haciendo una interpretación a sensu contrario, el heredero real no podrá reivindicar los bienes transmitidos por el heredero aparente al tercero de buena fe.

El reseñado en el párrafo anterior es un ejemplo que descansa en una situación fáctica. También lo es y contribuye a comprender la aplicación de la protección al tercero basada en la teoría de la apariencia, lo regulado en el artículo $\left(948^{\circ}\right.$ del código civil):

Quien de buena fe y como propietario recibe de otro la posesión de una cosa mueble, adquiere el dominio, aunque el enajenante de la posesión carezca de facultad para hacerlo. Se exceptúan de esta regla los bienes perdidos y los adquiridos con infracción de la ley penal.

Y es que ciertamente, existe la presunción (destruible) de que quien posee una cosa mueble es propietario de la misma, motivo por el cual (por ejemplo) si una persona compra un reloj o un lapicero fino a otra, creyendo que es el propietario, será amparado y mantenido en su adquisición, a pesar de que mañana aparezca el verdadero propietario haciendo el reclamo correspondiente. En este supuesto, ha sido la publicidad fáctica que otorga la posesión, la que ha generado una apariencia, pues quien tiene en su muñeca el reloj materia de venta es tenido por propietario, a pesar de que no lo sea. Téngase en cuenta que, si el poseedor del reloj es también su propietario, no estamos en estricto ante una apariencia, sino ante la realidad, y en esa medida no entra en juego la teoría que venimos comentando.

El Diccionario de la lengua española (Real Academia Española, 2014) define el término "apariencia" en su tercera acepción como "Cosa que parece y no es", con lo cual queda claro que existen dos espacios claramente diferenciables: a saber, la realidad (lo que es) y la apariencia (lo que parece, pero no es). Álvarez Caperochipi (2005) sentencia a propósito de lo aquí tratado, que "la realidad no existe" (p.16). Apartándonos de esta posición extrema del profesor, sostenemos que la realidad sí existe, pero en buena cuenta, es menos importante que la apariencia bajo la premisa de que debe protegerse y 
privilegiarse al tercero que confía en esta última. Más bien, acogemos la posición de Álvarez Caperochipi (2005) cuando indica que:

La protección de la apariencia es un principio básico para erradicar la violencia y garantizar la paz social, (;) la posesión y el registro dan seguridad, elasticidad y rapidez al tráfico económico que no puede detenerse en investigaciones minuciosas; la moral jurídica es una moral resultativa que, por ello mismo, no puede atender sino apariencias; y en derecho la realidad es siempre inseparable de su prueba. (p.16)

En lo que respecta a la vinculación entre el registro y la apariencia, hay que decir que fundamentalmente de lo que se trata es de proteger al tercero que confía en lo que se publicita a través del registro, lo cual discuerda necesariamente de la realidad jurídica. Y ¿Qué es la "realidad jurídica"? Pues depende del "tercero" al cual estemos haciendo referencia. Efectivamente, si nos atenemos al Registro Mercantil, advertimos que hay dos tipos de "tercero" que deben ser protegidos, a propósito de la apariencia generada desde y por el registro:

a) El llamado tercero de inoponibilidad registral, para quien lo no inscrito (que existe) le es inoponible, el cual será amparado de actuar conforme al registro. En este caso, la realidad jurídica es lo no inscrito; y,

b) El llamado tercero de fe pública registral, para quien la realidad es que el acto inscrito es nulo o inexistente; pese a ello, será amparado de actuar basándose en dicha inscripción que contiene aparentemente un acto válido o existente.

Es menester aclarar que ambos "terceros" a que se alude en las líneas que anteceden, deben reunir determinados requisitos para ser amparados completamente por el ordenamiento jurídico, conforme se verá más adelante; estos requisitos vienen determinados por los principios de oponiblidad/inoponibilidad y de fe pública registral en cada caso, aplicados al registro mercantil. Sin embargo, "concurrentemente" a los requisitos que plantea cada uno de los principios indicados, la teoría de la apariencia contiene a su turno sus propios requisitos (algunos coincidentes) que procedemos a formular. Para tal fin vamos a seguir a De Eizaguirre (1999) y a Vicent Chuliá (2006):

a) Debe existir un hecho de apariencia, elevado expresamente por la ley a digno de este régimen especial. (Vicent Chuliá, 2006, p.124) 
b) La imputabilidad del hecho de apariencia a quien responde legalmente de él, aquí el comerciante, que no respondería si aquella circunstancia le fuera inimputable, como en caso de actuación delictiva. Piénsese el poder otorgado a un mandatario de la sociedad mercantil de manera fraudulenta. (Vicent Chuliá, 2006, p.124)

c) El confiante, tercero respecto del causante del supuesto base de la confianza, ha de actuar de buena fe. (De Eyzaguirre, 1999, p.231). Dicho requisito, a nuestro juicio y a contrario de lo que piensa el autor, se limita a la falta de conocimiento positivo de la verdadera situación jurídica, sin llegar al extremo de exigir culpa grave.

Finalmente en cuanto a los requisitos que plantea la teoría de la apariencia para su aplicación, hay que mencionar que tanto De Eizaguirre (1999) como Vicent Chuliá (2006) proponen coincidentemente como un cuarto y último requisito, que se haya producido una relación de tráfico onerosa, tomando como referencia o analogía lo prescrito en el artículo $34^{\circ}$ de la Ley Hipotecaria Española (el equivalente al artículo $2014^{\circ}$ del código civil peruano), que reclama onerosidad al tercero que pretende protección al amparo del principio de Fe Pública Registral.

De entrada hay que mencionar que discrepamos de los autores citados en este extremo de su exposición pues consideramos que la onerosidad, si bien calza y es admisible -aunque siempre discutible-para aplicar la Fe Pública Registral en los registros de bienes, existen otros supuestos en que no necesariamente habrá de requerirse la citada onerosidad; para muestra, baste citar el Principio de Oponibilidad Registral, el cual prescinde de la onerosidad no solo en el Registro de la Propiedad, sino también en el Registro Mercantil.

De tal forma que, en abono de construir y definir sistemáticamente los requisitos que propone la Teoría de la Apariencia en general, no debemos considerar la onerosidad como nota característica, sino que en cada caso en particular deberá evaluarse su necesaria o innecesaria presencia. En todo caso, en los dos capítulos siguientes en los que pretendemos delimitar la naturaleza y características del tercero mercantil de oponibilidad y del tercero mercantil de fe pública registral, nos extenderemos sobre el aspecto de la onerosidad. 


\section{CAPÍTULO II: EL TERCERO DE OPONIBILIDAD MERCANTIL}

Cuando estudiamos los registros públicos, decididamente debemos analizar el mundo del tercero registral o mejor aún, de los terceros registrales.

Ordinariamente y a propósito del estudio del "contrato" como fuente creadora de obligaciones para las partes que se vinculan, se piensa que dichos actos jurídicos sólo tienen efectos inter partes; es lo que se ha venido en llamar "la relatividad de los contratos" en virtud a la cual los efectos jurídicos que éstos despliegan involucran por principio a quienes celebraron el contrato.

Sin embargo, lo cierto es que no en pocas ocasiones y a partir de las situaciones jurídicas generadas por dichos contratos, o determinados hechos con incidencia jurídica en general, hay personas - naturales o jurídicas- ajenas a las partes del contrato, que de alguna forma se ven afectadas por los efectos jurídicos generados sea potencial o realmente (definitivamente no estamos haciendo alusión a los herederos de las partes del contrato)

Nuestro código civil de 1984 así lo prevé en su artículo $1363^{\circ}$ cuando indica que "Los contratos sólo producen efectos entre las partes que los otorgan y sus herederos, salvo en cuanto a éstos si se trata de derechos y obligaciones no transmisibles." (Código Civil, 2014)

Estas personas ajenas a la celebración del contrato son entonces "terceros" y hablar del tercero desde el punto de vista civil, tiene determinadas implicancias cuyo foro no es el presente para estudiar; más bien, hay un tercero que es ajeno a ciertas relaciones o situaciones jurídicas, pero a quien definitivamente le interesa las consecuencias de aquellas y la forma más simple de informarse es a través los registros públicos.

Así lo ha considerado el legislador y por ello, en el caso del derecho societario, ha considerado que determinados hechos deben inscribirse. Como señalan Madriñan de la Torre y Prada Márquez (2013): 
Hay hechos y actos jurídicos cuya ocurrencia y realización no es indiferente a los terceros, quienes, por virtud de la interrelación que supone la vida en sociedad, deben conocer para seguridad y claridad en sus negocios... Con el fin de dar respuesta adecuada a estas necesidades, y para asegurar el orden y la confianza que deben presidir las relaciones jurídicas, se han ideado sistema de publicidad e información en beneficio de terceros, como el registro público mercantil. (p.133)

Por lo pronto y en aras de limitar la investigación podemos identificar hasta cuatro "terceros registrales", los cuales no son siempre conocidos o reconocidos por la doctrina, cada uno con características propias y bien diferenciadas:

a) El tercero registral del artículo $2014^{\circ}$ del código civil, equiparable al tercero hipotecario español del artículo $34^{\circ}$ de la Ley Hipotecaria Española; este tercero está adscrito a los registros de bienes y se vincula íntimamente con el Principio de Fe Pública Registral.

b) El tercero registral del artículo $2022^{\circ}, 1708^{\circ}$ y otras normas del código civil, los cuales son equiparables en alguna medida al tercero del artículo $32^{\circ}$ de la Ley Hipotecaria Español; este tercero también está adscrito a los registros de bienes y está íntimamente vinculado al Principio de Oponibilidad / Inoponibilidad Registral.

c) El tercero registral de los artículos $25^{\circ}, 26^{\circ}$ y $29^{\circ}$ del código de comercio, los cuales están adscritos al registro mercantil o societario y están íntimamente vinculados al Principio de Oponibilidad / Inoponibilidad Registral.

d) El tercero registral del artículo IV del Título Preliminar del Reglamento del Registro de Sociedades, equiparable al tercero regulado en el artículo 20.2 del Código de Comercio Español y al artículo $8^{\circ}$ del Reglamento del Registro Mercantil; se vincula íntimamente con el Principio de Fe Pública Registral.

Nótese que el unico tercero registral que no ha sido regulado por una norma con rango de ley, es el detallado en el literal d) que antecede, lo cual implica que sea harto discutible su existencia y eficacia en el ordenamiento jurídico peruano; sobre este volveremos en el numeral 3.3 .

En razón al objeto de esta investigación queda claro que nos vamos a referir a los terceros descritos en los numerales c) y d) aludidos en los párrafos anteriores, para cuyo 
efecto resulta interesante delimitar quién es el tercero mercantil. Siguiendo a Gonzales Barrón (2013) diremos que el tercero es aquel que entra en relación negocial directa con la sociedad; el que contrata con ella, por lo cual se trata casi de un "segundo", antes que de un "tercero", en sentido riguroso. Por eso, este tercero no es aquel que carece de la condición de parte de un negocio jurídico, sino aquel que no es el sujeto de la inscripción. Un ejemplo servirá para aclarar el concepto: la sociedad A vende mercaderías en virtud de un poder inscrito; los terceros serán todos aquellos compradores (por ejemplo, B) que contraten con la sociedad. Si dijéramos que tercero es "aquel que no es parte", entonces $\mathrm{B}$, que sí participa en el negocio como comprador con A vendedor, no sería un tercero; por tal motivo, esa definición debe descartarse. En cambio, en el registro de personas, el tercero es aquel que "no es el sujeto inscrito", por cuanto el registro sólo publica el acto de apoderamiento otorgado por la sociedad A; y el tercero B es ajeno a ese acto interno. En este punto, la cuestión es pacífica en doctrina. Así, "tercero será toda persona distinta del causante de la inscripción, es decir, la persona a quien perjudica la inscripción y a quien favorece la no inscripción” (Gonzales Barrón, 2013, p. 82).

Conforme a lo dicho, tenemos ya identificado en términos generales al tercero registral del registro mercantil, diferenciándolo del tercero registral del registro de bienes.

Ahora más bien, nos interesa en este apartado establecer quién es el tercero registral vinculado a la oponibilidad o a la inoponibilidad registral; lo vamos a llamar para simplificar las cosas, pues la ley no le atribuye un nombre propio, tercero mercantil de inoponibilidad registral.

En principio es aquel al cual hemos aludido en el literal c) que antecede; por tanto, su regulación viene con una norma con rango de ley como es el Código del Comercio. Llama poderosamente la atención que basándose en un principio registral reconocido, no se le haya recogido en el Título Preliminar del Reglamento del Registro de Sociedades, como sí se ha hecho más bien con el Principio de Fe Pública Registral que no aparece regulado en nuestro código de comercio.

En términos generales, sin perjuicio de su análisis mayor en los apartados posteriores de este capítulo, podemos decir que dicho tercero "No es otro que aquel que no ha sido parte en el acto que pretende oponérsele y quien, a su vez, puede invocar a su favor lo inscrito. (Gonzales Loli, 2010, p. 243). 
A pesar de las normas especiales que regulen al tercero mercantil de inoponibilidad registral, (por ejemplo en la Ley General de Sociedades), consideramos que el artículo rector de la inoponibilidad en el registro societario viene a ser el artículo $26^{\circ}$ del Código de comercio, que a la letra reza que "Los documentos inscritos sólo producirán efecto legal en perjuicio de tercero desde la fecha de su inscripción, sin que puedan revalidarlos otros, anteriores o posteriores, no registrados."

Esta norma recoge la llamada publicidad registral positiva, esto es, que lo inscrito afecta a los terceros, no pudiendo éstos invocar desconocimiento de lo inscrito; ello en virtud a la cognoscibilidad prescrita en el artículo $2012^{\circ}$ del Código civil (presunción iure et de iure de que todos conocen el contenido de las inscripciones).

La publicidad registral negativa es consecuencia lógica, o si se quiere, la otra cara de la publicidad positiva, pues el artículo $26^{\circ}$ del código citado leído en contrario indica que, los documentos no inscritos, no producen efecto legal en perjuicio de tercero. Así sucede también en el caso español donde De Eizaguirre (1999) señala que

Por mor de concisión, el artículo 21 I CCom regula, en una sola frase, tanto el efecto de oponibilidad del contenido del RM, como la denominada publicidad negativa; motivo por el cual, al igual que al tratar de la inoponibilidad (4), hemos de hacer referencia a la misma norma. De esta suerte, sin embargo, al precisar las condiciones de oponibilidad se invierte el orden natural de las cosas; convirtiéndose la oponibilidad, de regla en excepción (sólo). Al revés, la publicidad negativa se desprende de modo implícito, "a contrario" de la formulación legal. (p. 234)

\subsection{La Oponibilidad Registral: fundamento y características}

Conforme señala Pau Pedrón (como se citó en Gonzales Loli, 2010):

Uno de los rasgos esenciales de los Registros de seguridad jurídica es la oponibilidad, entre otros rasgos o principios registrales. Desde la perspectiva de la eficacia de esos Registros éste es el único rasgo común a todos ellos (no en todos ellos rige el principio de fe pública registral ni el de prioridad.) El sujeto activo de la oponibilidad registral es el titular inscrito, y sujeto pasivo es todo tercero, inscrito o no. (p. 248) 
El fundamento de la oponibilidad viene dado por la confianza en la publicidad del registro, sea de lo inscrito como de lo no inscrito. Así lo hemos reseñado cuando hemos tratado del Principio de Apariencia Jurídica, como base para la aparición y regulación de los diversos terceros registrales y de entre ellos, el tercero de oponibilidad registral mercantil.

Este principio tiene aplicación únicamente cuando estamos en presencia de inscripciones declarativas, en las cuales justamente existe un acto o hecho jurídico que se configura o constituye fuera del registro, pero que para fines de afectación hacia terceros se inscribe en el Registro, limitándose por ello este último tan sólo a “declarar” el acto o hecho jurídico ya existente, ya constituído.

Por esta razón, en el apartado anterior (véase el literal c), no hemos considerado al artículo $24^{\circ}$ el código de comercio como uno que recoge el principio de inoponibilidad; el mismo indica que "Las escrituras de sociedad no registradas, surtirán efecto entre los socios que las otorguen; pero no perjudicarán a tercera persona, quien sin embargo podrá utilizarlas en lo favorable", regulando así la constitutividad para la obtención de la personería jurídica de las sociedades mercantiles. En esa medida, el problema no puede ser de oponibilidad o inoponibilidad registral, sino que -consideramos-, se trata de la existencia o inexistencia de la persona jurídica, en razón a su inscripción, o a la falta de ésta.

El hecho de que el contrato de sociedad no inscrito sea válido y la sociedad (irregular) pueda vincularse, no enerva el que nos encontremos ante un problema de inexistencia de la persona jurídica. No se debe perder de vista que la sociedad irregular es un ente distinto a la sociedad como persona jurídica constituida apropiadamente. Conforme a De Eizaguirre (1999)

En determinados supuestos el efecto jurídico perseguido no se alcanza sin la inscripción en el RM; porque el ordenamiento jurídico ha incluido como elemento del supuesto de hecho la inscripción. Tal es el caso, v. gr. de la sociedad anónima, que adquiere su personalidad jurídica no tan sólo en virtud de la escritura de constitución, sino que precisa de la inscripción de la misma en el RM (art. $7^{\circ} \mathrm{I}$ LSA). La inscripción forma parte, en tal caso, del supuesto de hecho de la SA, o es condición indispensable para su existencia. (p. 227) 
Por una cuestión de justicia terminógica y debido conocimiento de la naturaleza de las cosas, insistimos entonces que en el caso de las inscripciones constitutivas, no habrá que referirse al principio de oponibilidad, sino a la existencia o inexistencia. Madriñan de la Torre y Prada Márquez (2013) citan una jurisprudencia de la Corte Suprema de Justicia de España, Sala de Casación Civil, sent. de 30 de noviembre 1994, mag. ponente Hector Martín Naranjo y deja en claro que:

No es que la inoponibilidad sea asimilable a la inexistencia, puesto que la última no es una sanción que se impone al negocio, o sea, que este, en sí mismo existe o no existe, tanto frente a las partes, como frente a terceros, mientras que en aquella el negocio existe, solo que no produce efectos respecto a otros. (p. 153)

De otro lado, hay que tener en consideración que la oponibilidad está íntimamente ligada al principio de tipicidad registral, en virtud al cual sólo se pueden inscribir en el registro aquellos actos que el legislador ha previsto como de necesaria oponibilidad a través de la publicidad registral. Efectivamente, imagine el lector lo que sucedería si se pudiera inscribir cualquier hecho o acto de comercio en el registro público, supeditada dicha decisión al mero arbitrio del comerciante o gerente de la sociedad; definitivamente, se disiparía la oponibilidad pues ingresarían todo tipo de actos, de entre los cuales habrían actos de mero trámite, actos con conenido interno, actos que no afectan a ningún tercero, entre otros, y entonces, los terceros no sabrían en estricto qué les es oponible y qué no.

Rojo (2004) justamente da cuenta que el principio comentado prescribe la característica de numerus clausus cuando se trata de actos inscribibles en el Registro Mercantil, lo cual sucede también en el Perú; así, indica que

La inscripción de sujetos y actos en el Registro mercantil está sometida al llamado principio de tipicidad: existe un numerus clausus de sujetos y de actos inscribibles. Solamente son inscribibles en los Registros mercantiles territoriales aquellos sujetos y aquellos actos determinados por la Ley (art.16.1 C. De C.) y por el Reglamento del Registro mercantil (art. 2, letra "a", RRM). La limitación de los actos inscribibles es exigencia lógica de la propia finalidad del sistema registral mercantil. El Registro tiene por objeto publicar frente a terceros hechos relevantes. Si se dejase abierto el Registro a actos no previstos por norma legal o reglamentaria, no sólo se produciría gran incertidumbre acerca del contenido potencial de la hoja registral, sino que sería inadmisible, por el grave daño que 
ocasionaría a los terceros, dotar de oponibilidad a aquellos actos inscritos y publicados que hubieran accedido al Registro por la mera decisión del interesado. (p. 108)

La oponibilidad constituye uno de los efectos principales de la publicidad que emana del registro, y tiene una doble vertiente: aquella que se refiere al aspecto positivo, en virtud a la cual, lo inscrito se presume conocido por todos, o si se quiere, nadie puede alegar ignorancia al respecto; y la publicidad en su aspecto negativo, en virtud a la cual, aquello que no se inscriba, no perjudicará a los terceros para quienes el acto o hecho se tiene incluso por inexistente.

Estas dos vertientes o aspectos de la publicidad material del registro son importantes de tener en cuenta, pues según nos encontremos en el marco de la publicidad negativa o positiva del registro mercantil, existen determinados temas a considerar para que se configure el principio de oponibilidad en cada caso; sin perjuicio de ellos es menester señalar que, a pesar de existir estas dos vertientes, el tercero registral de oponibilidad mercantil es uno solo, por lo cual nuestro objetivo es delimitar las características que lo harán merecedor de la protección jurídica que el ordenamiento brinda a partir del registro.

\subsection{EI Tercero Registral Mercantil de Inoponibilidad}

Es importante iniciar este apartado recordando nuestra aseveración del apartado anterior, en el sentido de que la oponibilidad "como principio registral" sólo existe en los registros o en las inscripciones declarativas, siendo que la inscripción tiene como función principal publicitar hacia terceros los actos ya configurados extrarregistralmente, generando con ello diversos efectos jurídicos; de entre ellos, la oponibilidad registral y su correlato, la inoponibilidad registral.

En abono de lo dicho, coincidimos en que

Es necesario diferenciar claramente dos planos: primero, el del hecho jurídico, que existe y es válido; segundo, el de la publicidad de ese hecho. En el caso de las inscripciones con efecto declarativo, que son la mayoría en el Registro de Sociedades, la diferencia de planos es evidente: el hecho jurídico existe y es válido sin necesidad de inscripción (por ejemplo, el otorgamiento de un poder), 
pero otra cosa es la publicidad de ese hecho -que antes ya era un "ser"-, la cual conlleva determinados efectos o consecuencias jurídicas. (Gonzales Barrón, 2013, p. 90)

Siendo así, es lícito preguntarnos si ante una eventual colisión de intereses podríamos preferir la realidad registral, es decir, el acto publicado a través de las partidas del registro, o el acto mismo, el cual existió antes de ser reflejado en los libros del registro.

Pues lo cierto es que el hecho o acto como tal, en su estado extrarregistral, es válido y eficaz si cumple con los requisitos previstos en las normas sustantivas, motivo por el cual, las normas societarias prevén la posibilidad de que el tercero utilice en su favor las consecuencias jurídicas de un hecho no inscrito (inoponible por ellos a todos), pero del cual sí se puede servir el tercero que conoce efectivamente del hecho y así se lo hace saber a la sociedad. A guisa de ejemplo, léase el artículo $29^{\circ}$ del código de comercio, el cual reza que "los poderes no registrados producirán acción entre el mandante y el mandatario; pero no podrán utilizarse en perjuicio de tercero, quien sin embargo, podrá fundarse en ellos en cuanto le fueren favorables". (El resaltado y la cursiva es nuestra)

De la misma forma, pueden leerse muchas normas de la Ley General de Sociedades como por ejemplo el artículo $16^{\circ}$, que alude a los plazos para inscribir determinados hechos jurídicos en el Registro, y que finalmente sanciona que "toda persona puede ampararse en los actos y acuerdos a que se refiere este artículo para todo lo que le favorezca, aún cuando no se haya producido su inscripción.” Comentando este artículo en la doctrina nacional, Elías Laroza (1999) menciona que

Mediante esta disposición, que es un acierto introducido por la nueva LGS, cualquier socio o tercero puede reclamar que resulten oponibles a la sociedad y con plenos efectos todos los actos o acuerdos celebrados válidamente por la misma que modifiquen su régimen interno y que aún no hayan sido inscritos en el registro por negligencia de los otorgantes o administradores, siempre que le favorezcan. (p. 51)

Esta posibilidad del tercero de ampararse en lo no inscrito y hacerlo "oponible" para él, nos hace recordar por un lado que la oponibilidad no es un concepto propio del derecho registral, sino que más bien, como concepto jurídico importa hacer que el otro respete las consecuencias jurídicas de un hecho o acto jurídico. Así por ejemplo, el derecho de 
propiedad que una persona ostenta sobre un reloj es oponible a todos los demás, quienes no podemos tomar el reloj para nosotros. Cosa distinta es entonces la mera "oponibilidad" que la "oponibilidad registral", que es entonces -utilizando los términos esbozados en este párrafo-hacer que el otro respete las consecuencias jurídicas de un hecho o acto jurídico, a partir de lo que figura en las partidas del Registro.

De otro lado, este favorecerse de lo no inscrito, recibe el nombre en doctrina de la llamada "utilizabilidad", que sería una especie del género "invocabilidad”. (Casado Urbano, 2002) da cuenta del reconocimiento y aceptación que hace la doctrina de esta posibilidad, indicando que

Como señala Pau Pedrón (2001), se permite que el tercero utilice en su beneficio el conocimiento de hecho, aunque no se haya realizado inscripción o publicación, o ninguno de los dos mecanismos complementarios de publicidad. Farias prefiere denominar este concepto específico, que, entiendo, incluido dentro del género de la invocabilidad, como utilizabilidad, que significa "aquella posibilidad que tiene el tercero de invocar en su favor el conocimiento que, vía publicidad de hecho, tiene de los datos no inscritos" y sitúa su fundamento último, precisamente, en la doctrina de protección de confianza en la apariencia y en la doctrina de los actos propios. (p. 354)

A modo de paréntesis a tener en cuenta, no podemos dejar de mencionar que la utilizabilidad tiene sus detractores, pues:

No es posible que el tercero se apoye en la realidad extrarregistral y en la registral, conociendo ambas (K. SCHMIDT); o, lo que es lo mismo, que invoque de una escritura de sociedad o de poder no inscrita unas cláusulas y pretenda ignorar otras ("teoría de la doble opción"), ya que iría contra la buena fe. (Vicent Chuliá, 2006, p.147)

Siendo así, podemos concluir válidamente que la registración del hecho no le adiciona nada al acto en sí al acto mismo, sino que lo irradia "hacia fuera", para que los terceros no puedan alegar desconocimiento del mismo.

Ante lo dicho es válido citar a Paz-Ares quien sostiene que

En realidad, la oponibilidad, que no es más que el reverso de la publicidad negativa, no puede catalogarse de efecto propio del Registro, puesto que sólo 
opera cuando la realidad extrarregistral coincide con la registral, debiendo entenderse, por tanto que el efecto lo produce la realidad y no el Registro [cursivas añadidas] (citado por Casado Urbano, 2002, p.351)

Con lo dicho hasta acá, podemos ya perfilar una primera característica del tercero registral de oponibilidad mercantil: la buena fe. Como es bien sabido, la buena fe en materia registral equivale a "desconocimiento": por un lado, cuando se trata del principio de fe pública registral, se refiere justamente al desconocimiento de cualquier vicio que pudiera decretar la ineficacia del acto por el cual adquirió titularidad quien transfiere; y, en el caso de la oponibilidad, si hablamos de la publicidad negativa, la buena fe importa el desconocimiento o ignorancia de lo no inscrito. En este último caso, ante el hecho de la no inscripción, el tercero no tiene que probar nada pues simplemente alegará que desconocía; sin embargo, si el comerciante o la sociedad hubiere cursado comunicación fehaciente al tercero de la existencia de determinado hecho (piénsese por ejemplo, en la revocatoria de un poder), no estaremos ante la presencia de un tercero de buena fe. Empero no debemos olvidar que "Naturalmente, como ya hemos señalado, la buena fe de ese tercero se presume" (Rojo, 2004, p. 118).

Debe quedar claro que, en el caso de la publicidad positiva, es decir, la presunción de que todos conocen lo inscrito, lo que existe es un perjucio hacia los terceros, quienes no podrán alegar ignorancia de la realidad extrarregistral, la cual se ha equiparado a la realidad registral con la inscripción. Recuérdese al efecto parte del tenor del artículo $26^{\circ}$ del código de comercio: "Los documentos inscritos sólo producirán efecto legal en perjuicio de tercero [cursivas añadidas] desde la fecha de su inscripción".

"Merced a la oponibilidad se neutraliza la posible invocación de buena fe por parte del tercero; la oponibilidad opera con independencia de que el tercero conozca o no los hechos publicados.” (Casado Urbano, 2002, p.351)

Más bien la protección al tercero registral mercantil de inoponibilidad se produce a partir de la publicidad negativa, es decir, tener por inexistente aquello que no se inscribió. Conforme a De Eizaguirre (1999)

A diferencia del efecto de oponibilidad, la publicidad negativa tiene un contenido eminentemente protector... Merced a dicha norma resulta tutelada la confanza del 
tercero de buena fe en la vigencia de una situación jurídica, que ya no corresponde a la realidad, pero no se halla desmentida por el RM. Incluso cabe que la apariencia resulte del contenido desactualizado del propio RM. (p. 234-235)

En añadidura habría que decir que el fundamento de la protección al tercero que venimos analizando viene dado por la teoría de la apariencia, pero también por el hecho indiscutible de que la sociedad pudo modificar a su solo arbitrio la realidad que refleja el registro, por tanto, siendo ella la protagonista y principal cuando no única responsable de lo que se inscribe, debe soportar el manto protector que se despliega por ley hacia el tercero.

Finalmente entonces, siguiendo las ideas de Casado Urbano (2002) y De Eizaguirre (1999) podemos concluir que el tercero registral mercantil de inoponibilidad debe ser uno de buena fe; quien está eximido de probar que ignoraba el acto no inscrito; quien puede verse favorecido por lo no inscrito si así lo hace saber a la sociedad; pero a quien se le puede enervar la buena fe notificándole fehacientemente y oponiéndole por tanto el acto no inscrito; debiéndose existir además la buena fe aludida en el momento en que se vinculan jurídicamente el tercero con la sociedad; la norma tampoco refiere a una especial diligencia o culpa, al momento de valorar la buena fe; el tercero ha de tener conocimiento del supuesto base de apariencia; no se exige imputabilidad a la sociedad por la no inscripción (puede tratarse de un atraso o negligencia del Registrador); y finalmente, como dice textualmente De Eizaguirre (1999):

La actuación del tercero protegido por la publicidad negativa ha de ser relativa a un acto de carácter negocial o procesal. Este requisito no resulta del texto legal, pero es congruente con la protección conferida a la apariencia en que se basa la norma legal. La confianza tutelada por la norma es aquella que induce al confiante a realizar un acto correspondiente a la apariencia suscitada, calificado de "acto de disposición" o "inversión de confianza". Por ello, la publicidad negativa no tutela, en principio, al tercero "no activo", es decir, víctima de un acto ilícito. (p. 238)

De otro lado, y tomando como referencia en lo que fuere aplicable a nuestra legislación, los presupuestos establecidos por Casado Urbano (2002) para la efectividad del principio de oponibilidad, diremos que para que opere la publicidad positiva y efectivamente la inscripción perjudique al tercero (es, decir que, en este caso no será protegido), se requiere: 
a) Que lo que se busca oponer sean actos susceptibles de inscripción. (p. 343).

b) El tercero afectado por la oponibilidad del derecho inscrito es tanto el que inscribe como el que no inscribe (tercero civil) (Gonzales Loli, 2010, p. 249).

c) Que los actos a oponerse sean capaces de originales a los terceros algún perjuicio (p. 346).

d) Siguiendo a Pau Pedrón (2001), que la situación sea legal (p. 351), o como indica Gonzales Barrón (2013), que, el hecho jurídico existe y es válido (p. 92).

e) Y, finalmente, que el acto se inscriba. Como señala Pau Pedrón (2001): "la legalidad de la situación jurídica es un requisito necesario pero no suficiente... es necesaria su inscripción y es la inscripción la que hace posible la oponibilidad" (p.351). 


\section{CAPÍTULO III: EL TERCERO DE FE PÚBLICA REGISTRAL MERCANTIL}

Uno de los principios registrales más trascendentales del sistema registral peruano es sin duda el Principio de Fe Pública Registral, el cual ha sido recogido en el artículo $2014^{\circ}$ del código civil peruano.

Dicho principio definitivamente implica la consagración de la aseveración aquella que divide al sistema de derecho común, con el sistema registral. Y es que para fines estrictamente didácticos, aun cuando el sistema jurídico peruano es uno solo, podemos dividirlo o hacer referencia a dos subsistemas jurídicos: uno de derecho común y otro, el registral. Cada uno de ellos ostenta principios jurídicos propios que los caracteriza, en cuyo caso, los efectos jurídico - sustantivos difieren en su solución ante un mismo problema.

Así por ejemplo, ante el fenómeno de la transferencia del derecho de propiedad que recae sobre un inmueble, al derecho común le basta en virtud a lo prescrito en el artículo $949^{\circ}$ del código civil la formación del llamado consentimiento en sede contractual, por lo cual no se requiere siquiera la instrumentalización en documento alguno del acuerdo para que opere la transferencia de una esfera patrimonial a otra. Esa dinámica sin embargo es desconocida por el sistema registral, pues para este último, sólo será reconocido propietario del inmueble quien aparezca como tal en las partidas del registro de la propiedad.

Lo mismo sucede por ejemplo con los poderes y sus modificaciones o revocatorias, los cuales no tienen que inscribirse para ser válidos o eficaces; sin embargo, el sistema registral peruano desconocerá una revocatoria de poder no inscrita, y así, aun cuando la revocatoria sea válida y en principio eficaz, no lo será para los terceros, quienes podrán ampararse en el poder otorgado para contratar, en la medida que desconozcan de la revocatoria operada, manteniendo los derechos adquiridos, de ser el caso.

En el caso de la fe pública registral, un no titular de determinado derecho puede transferirlo a un tercero y éste, en la medida que reúna determinados requisitos, será 
mantenido en su derecho y amparado absolutamente por el ordenamiento jurídico. Dicha solución repugna definitivamente al sistema de derecho común, pues es inconcebible a los ojos de cualquier ciudadano que una persona que no sea propietaria de algo lo pueda vender, por lo cual podemos decir que en este supuesto también difiere la solución de los dos subsistemas ante un mismo problema jurídico planteado. Veamos un ejemplo.

Piénsese en una persona que no es propietaria de determinado bien -un reloj costoso- y que lo usa una noche pues su hermano se lo prestó para una fiesta, empero esta persona lo vende a un tercero por determinado precio. Pues bien, en ese caso, el derecho común rechaza la adquisición del reloj y la protección al tercero adquirente, pues quien transfiere no es el propietario (verus dominus), lo cual tiene sentido lógico y sirve como regla general. ${ }^{4}$ De otro lado mas bien, imaginemos en caso de un predio valioso el cual es transferido por quien figura inscrito en los registros públicos como propietario, pero que ciertamente no lo es, estando viciado su título adquisitivo al punto que resulta nulo o ineficaz. Pues bien, si en este supuesto dicho titular registral transfiere a un tecero quien reune determinadas caacterísticas, este último será mantenido en su derecho y protegido de manera absoluta por el ordenamiento jurídico. Nótese que en este caso el tercero está adquiriendo de quien no es realmente propietario (se trata de un non domino), sin embargo, el Derecho lo protege.

Vemos pues que las soluciones varían (mantener o no al tercero adquirente en su derecho), pese a que se trata de un mismo problema (la transferencia de propiedad por parte de un no propietario). La presente investigación nos permitirá establecer si en el caso del derecho mercantil, serán también protegidos de manera absoluta aquellos que contratan en base a la información que brinda el Registro Societario y si la norma que regula dicha protección es la adecuada, es decir, se incardina perfectamente en el ordenamiento jurídico peruano.

A este personaje que contrata con la sociedad mercantil, confiando en lo que manifiestan los asientos del Registro lo vamos a llamar Tercero Societario de Fe Pública Registral, el cual como veremos debe reunir ciertas características para ostentar

$4 \quad$ Esa es la regla general que por supuesto, como toda regla admite excepciones ante determinados supuestos; así, el artículo $948^{\circ}$ del código civil preceptúa que "Quien de buena fe y como propietario recibe de otro la posesión de una cosa mueble, adquiere el dominio, aunque el enajenante de la posesión carezca de facultad para hacerlo. Se exceptúan de esta regla los bienes perdidos y los adquiridos con infracción de la ley penal." 
protección y cuyo origen en el caso peruano parte del artículo $2014^{\circ}$ del Código civil, habiéndosele regulado en el artículo $4^{\circ}$ del Reglamento del Registro de Sociedades (2001) aprobado por la Sunarp y que a la letra reza que

La inexactitud o invalidez de los asientos de inscripción del Registro no perjudicará al tercero que de buena fe hubiere celebrado actos jurídicos sobre la base de los mismos, siempre que las causas de dicha inexactitud o invalidez no consten en los asientos registrales.

\subsection{Fundamento de la Fe Pública Registral}

Definitivamente el Principio de Fe Pública Registral tiene como fundamento principal la Teoría de la Apariencia sobre la cual hemos hecho un esbozo en las páginas anteriores. Sin duda alguna, se trata también en este caso en particular de un tercero que confía en lo que publicita el registro y en base a la información allí detallada se vincula jurídicamente.

\section{Claro que}

Cuando hablamos de la confianza o la fe en la apariencia registral nos referimos a la confianza objetiva que proporciona el Registro de la Propiedad a los que adquieren tomando como base sus pronunciamientos, porque es la institución pública oficial creada por el Estado con el fin de publicar las facultades dispositivas de los titulares. Es decir, nos referimos a una buena fe objetiva, o sea, la resultante únicamente de los datos del asiento registral, como principio o idea tenidos en cuenta por el legislador para regular y fundamentar los resultados del principio de fe pública registral. Aparte está la buena fe subjetiva que es un requisito muy importante para la protección del tercero. (García García, 1993, p. 230)

Conforme al insigne hipotecarista García García (1993), se trata de

Aquel principio hipotecario en virtud del cual el tercero que adquiere en base a la legitimación dispositiva de un titular registral es mantenido en la adquisición a non domino que realiza, una vez que ha inscrito su derecho, con los demás requisitos exigidos por la Ley. (p. 227) 
Se puede apreciar de la cita que el profesor García García relaciona íntimamente el principio que estamos analizando ${ }^{5}$ con el de Legitimación Registral recogido en nuestro artículo $2013^{\circ}$ del código civil ${ }^{6}$, a lo cual hay que decir efectivamente que este último artículo establece de manera expresa la presunción de exactitud del asiento registral, la cual, aun cuando es una presunción iuris tantum, dota de plena eficacia al contenido el asiento mismo.

A guisa de ejemplo, si el asiento registral refleja la adquisición del derecho de propiedad por parte de una persona, ésta se encuentra legitimada para transferirle a un tercero el derecho adquirido. Sin duda que la Legitimación Registral constituye uno de los pilares del sistema registral peruano, pues gracias a éste, los operadores jurídicos pueden contratar confiados en que los datos que se publicitan son ciertos; definitivamente podrían no serlo, pues podrían ser nulos o incluso podría ya haberse modificado lo inscrito al tener el Perú un registro mayoritariamente declarativo, pero lo cierto es que, si no existiera este principio los costos de transacción serían muy altos, al punto que la contratación sería casi nula toda vez que quien quisiera adquirir un derecho tendría que recurrir a diversas y múltiples instancias para conocer o presumir quién es el verdadero titular del derecho que pretende adquirir.

${ }^{5}$ Artículo $2014^{\circ}$ del código civil. Principio de buena fe pública registral

El tercero que de buena fe adquiere a título oneroso algún derecho de persona que en el registro aparece con facultades para otorgarlo, mantiene su adquisición una vez inscrito su derecho, aunque después se anule, rescinda, cancele o resuelva el del otorgante por virtud de causas que no consten en los asientos registrales y los títulos archivados que lo sustentan.

La buena fe del tercero se presume mientras no se pruebe que conocía la inexactitud del registro.”

${ }^{6}$ Artículo 2013. Principio de legitimación

El contenido del asiento registral se presume cierto y produce todos sus efectos, mientras no se rectifique por las instancias registrales o se declare su invalidez por el órgano judicial o arbitral mediante resolución o laudo firme.

El asiento registral debe ser cancelado en sede administrativa cuando se acredite la suplantación de identidad o falsedad documentaria y los supuestos así establecidos con arreglo a las disposiciones vigentes. vigentes”.

La inscripción no convalida los actos que sean nulos o anulables con arreglo a las disposiciones 
Empero el Principio de Fe Pública Registral es uno que va más allá de la mera legitimación registral, pues su principal objetivo es proteger a un tercero que adquiere un derecho confiando en el registro y cumpliendo determinados requisitos que resultan ser rigurosos.

De la lectura del artículo $2014^{\circ}$ del código civil se advierte que el mismo está diseñado para operar en el registro de bienes, a propósito del tráfico de derechos sobre dichos bienes. En efecto, conforme indica Arias Schreiber Pezet (2006):

La consecuencia más relevante de este principio, según destaca la doctrina más reciente, es que genera una adquisición "a non domino" a favor del tercero adquirente toda vez que este ha adquirido de alguien que de buena fe fue dueño, y a pesar de eso es mantenido en su adquisición. (p. 860)

Nótese que strictu sensu, este principio reclama como requisito sine qua non que la relación jurídica que tuvo en su momento quien hoy transfiere el derecho, debe necesariamente estar viciada y por lo mismo, expuesta a ser decretada su ineficacia; pero más todavía, dicho(s) vicios (s) implican que el transferente sea calificado como un non domino (no titular) y sin embargo, a pesar de tal circunstancia, el tercero será protegido en la adquisición efectuada. ${ }^{7}$

Es por ello que el legislador impone al tercero que se ampara en este principio, requisitos de cierta particularidad, de entre los cuales destaca por ejemplo el de la onerosidad y cuya presencia en el principio bajo estudio la justifica magistralmente García García (1993) cuando indica que "en relación con el tercero del artículo 34 LH, que da lugar a una adquisición a non domino, estimamos justificado que el legislador exija el requisito de la onerosidad" (p.286)

Sobre el requisito de la onerosidad volveremos en las páginas siguientes cuando analicemos al tercero societario de fe pública registral, pero hasta aquí nos interesa destacar que el principio que venimos estudiando tiene como fundamento no desconocer la apariencia y confianza que despliega el registro, por un lado; pero del otro, nos interesa también llamar la atención en que siendo la protección que el ordenamiento jurídico dispensa al tercero "absoluta", es decir, que califica a su título adquisitivo de inacatable,

7 Si no hubiera vicio alguno, el principio en cuestión no opera y estaríamos de ser el caso, ante los principios de oponilidad y/o legitimación, pero no de fe pública registral. 
necesariamente tiene como premisa o supuesto normativo requisitos altamente rigurosos, ante cuya falta de siquiera uno de ellos la protección simplemente se desvanece o no surge.

Ahora bien, de entre las consecuencias que la fe pública registral acarrea, nos permitimos llamar la atención sobre dos que tienen especial importancia y que no deben quedar fuera del ámbito de análisis:

a) Lo primero a tener en cuenta es que este principio es una excepción a la llamada comúnmente "cascada de nulidades"; efectivamente, si tenemos en cuenta que a lo largo del historial de titularidades de un bien, alguna de éstas pudo estar viciada al punto que algún titular ostenta en determinado momento un título nulo, la consecuencia jurídica y lógica es que todo lo posterior a dicho acto es nulo pues ninguno de los posteriores titulares adquirió derecho alguno; sin embargo, la fe pública registral marca un hito dentro de la cadena de titularidades que mencionamos y ante la aparición del tercero registral (que reúne determinadas características), valida si se quiere la adquisición del derecho efectuada por este último; y a partir de allí, ordinariamente deberíamos estar en presencia de actos válidos y eficaces; y,

b) La existencia de este principio limita el llamado estudio de títulos, es decir el análisis que realizan los abogados para establecer si la adquisición de determinado derecho por parte de su cliente es segura, sólida y será mantenida en el tiempo como inatacable. Pues bien, como consecuencia de lo explicitado en el literal a) que antecede, en materia utilitaria, una de las virtudes de este principio es que no es necesario analizar todas las relaciones jurídicas anteriores que constan en el historial de la partida registral, sino que basta deternernos en la relación jurídica de quien pretende transferir el derecho al tercero registral y reunir los requisitos que plantea la norma $\left(2014^{\circ}\right.$ del código civil); todo lo anterioren principio es irrelevante para la protección del derecho adquirido. (Por supuesto, habrá que tener en cuenta las cargas y gravamenes que soporte el bien). 


\subsection{La Fe Pública Registral del Código Civil y el Tercero}

En el Perú, el Principio de Fe Pública Registral lo encontramos a nivel de norma con rango de ley regulado en el artículo $2014^{\circ}$ del código civil. Definitivamente es una norma de especial relevancia en el ordenamiento jurídico pues

Consiste en que cualquier tercero de buena fe que adquiera un derecho de aquel que ostenta la legitimación dispositiva de acuerdo a lo publicado por el Registro, esto es, el que contrata sobre la base de lo que proclama el Registro, será protegido una vez que inscriba su derecho, manteniendo su adquisición si luego resulta que quien se encontraba legitimado registralmente en realidad nunca lo estuvo. (Delgado Scheelje, citado por Arias Schreiber Pezet, 2006, p. 859)

Este principio ha sido malentendido frecuentemente, pues se ha considerado que, si alguien adquiere un derecho de un titular inscrito en los registros públicos y lo hace onerosamente y de buena fe, debe ser protegido bajo el auspicio del artículo $2014^{\circ}$ del código civil. Siendo así, se ha pretendido proteger a quien adquiere el derecho de propiedad de quien inmatriculó un predio y ahora transfiere. Definitivamente, en este caso no opera la llamada fe pública registral pues quien adquiere no es un tercero, sino más bien un segundo -en el registro-, siendo primero quien inmatriculó el bien.

La norma protege a quien se ha venido en llamar tercero registral, que es ciertamente un tercero en tanto es ajeno a la relación celebrada por quien pretende ahora transferirle (que es el segundo), quien a su turno adquirió de otro (que es el primero). Pero además es un tercero si se quiere cualificado, pues debe reunir determinados requisitos para gozar de protección absoluta e inatacabilidad de su título.

Como sabemos, el artículo $2014^{\circ}$ de nuestro código civil tiene como antecedente inmediato al artículo $34^{\circ}$ de la Ley Hipotecaria Española, siendo altamente similares en su contenido. Sobre el particular y a los fines de establecer qué cualidades debe tener el tercero registral de nuestro código civil, el profesor García García (1993) define que

De la interpretación de este precepto resultan los siguientes requisitos necesarios para que opere la protección registral al tercero del artículo 34 LH [2014º del código civil peruano]:

1..$^{\circ}$ Ha de tratarse de una adquisición por negocio jurídico realizada por el tercero, o asimilada a ella. 
$2^{\circ}{ }^{\circ}$ La adquisición en que interviene el tercero como parte ha de ser válida. (art. $33 \mathrm{LH})$.

$3^{\circ}{ }^{\circ}$ Es necesaria la previa inscripción de la finca o derecho a nombre del transmitente.

4. $\left.{ }^{\circ}\right)$ No ha de existir constancia en el Registro de causas de nulidad o de resolución del derecho del transmitente.

$\left.5^{\circ}\right)$ Ha de tratarse de adquisición a título oneroso.

$6^{\circ} .^{\circ}$ Es necesario que el tercero inscriba su adquisición.

7. ') El tercero del artículo 34 LH ha de tener buena fe. (p. 253)

Como se advierte fácilmente de los requisitos que debe reunir el tercero registral descrito, se trata en estricto de aquél que pertenece a los registros de bienes (entiéndase el registro de la propiedad inmueble y el registro de bienes muebles), los cuales definitivamente son distintos a los registros de personas (sean estas personas naturales o jurídicas).

Siguiendo a Gonzales Barrón (2013) queda claro que

La publicidad de los registros de bienes tiene claras diferencias con aquella de los registros de personas; tanto en el objeto que agrupa la información (el bien en uno y, la persona, en el otro), como -fundamentalmente- en la función y en los efectos que produce cada uno de estos registros. En cuanto a la función, el registro de bienes versa sobre objetos, con pretensión de estabilidad, en donde el historial jurídico emanado del registro se limita a contener solo aquellos actos que inciden sobre el bien. Por el contrario, en el registro de personas la publicidad informa sobre el historial de los sujetos, en donde los terceros toman como punto de partida esos datos, por lo que tiene incidencia en un número elevado de situaciones, con gran movilidad, y en el que la rapidez es la tónica dominante. (pp.78-79)

Definitivamente, la diferencia aquí establecida es trascendental para entender que el tercero registral de la fe pública registral del registro de bienes, es bastante distinto al tercero registral de la fe pública registral del registro societario. En el primer caso, si bien en razón a la oponibilidad erga omnes de los derechos reales los mismos se irradian potencialmente hacia toda la sociedad afectándola pasivamente en un primer momento, 
ya luego, cuando aparece el definitivo adquirente del derecho y que busca ampararse de lo regulado en el artículo $2014^{\circ}$ del código sustantivo, es fácilmente identificable el tercero registral, quien en añadidura para ser tal, debe inscribir su derecho. En tanto que, en el caso del tercero registral de fe pública del registro societario, es un personaje desconocido pues para ser tal no requiere inscribir su derecho, mereciendo aun así protección jurídica.

Como no es éste el apartado para explayarnos sobre el tercero de fe pública societario -sino en el siguiente-, baste por ahora decir que el Reglamento del Registro de Sociedades ha recogido, particularmente en su título preliminar, diversas normas y principios propios del Registro de la Propiedad Inmueble; sin embargo, por las diferencias acusadas en cuanto al objeto y función de cada uno de ellos, dicha asimilación normativa es discutible en algunos; así, en el Principio de Tracto Sucesivo y en lo que nos atañe, en el Principio de Fe Pública Registral.

Este parece ser un fenómeno inevitable, por un lado, desde que el mayor desarrollo doctrinal lo encontramos tanto en el Perú como en el derecho comparado, en el registro de la propiedad inmueble; de otro lado, porque desde el punto de vista operativo y de la publicidad formal, ambos registros pueden ser semejantes; de ello se ha dado cuenta en España, donde

En efecto, las sucesivas reformas del Registro Mercantil, desde la ya mencionada matrícula de comerciantes, lo han ido acercando cada vez más en su regulación y funcionamiento al probablemente mucho más conocido Registro de la Propiedad. (De los Ríos Sánchez, 2014, p. 221)

Pero hay que ser cautos al extremo cuando se pretenda exportar normas de un registro a otro. Como ha llamado la atención un notario español

El trasplante un tanto irreflexivo al ámbito del Registro Mercantil de toda la doctrina elaborada en torno al Registro de la Propiedad, es decir, lo que entre nosotros se conoce como "derecho hipotecario", con sus célebres principios. Siendo en la actualidad el Registro Mercantil, como luego precisaré, un registro no de bienes sino de sujetos, no es de extrañar que este trasplante suscite múltiples disfunciones si no se tiene el suficiente cuidado al deslindar el objeto y los 
destinatarios de uno y otro registro. (González-Meneses García-Valdecasas, 2005, p. 275)

\subsection{El Tercero Mercantil de Fe Pública Registral}

Canaris (como se citó en De Eizaguirre, 1999) acota que:

Entre las consecuencias favorables de la influencia del Derecho inmobiliario registral en la regulación del RM hay que señalar, sin lugar a dudas, la formulación del principio de fides pública; del que carecen otros ordenamientos mercantiles, obligados por ello a utilizar el equivalente de nuestro 21 III Ccom como único fundamento legal de la publicidad positiva. (p. 241)

Efectivamente, de manera ponderada algunos países han regulado en sus sistemas registrales el principio de fe pública registral aplicado no sólo a los registros de bienes, sino también al registro mercantil.

Vale mencionar sin embargo, que no es posible equiparar los registros de bienes con los registros de personas, pues conforme ya hemos reseñado en las páginas que anteceden, existen marcadas diferencias entre ellos, motivo por el cual no incidiremos más al respecto.

El objetivo de este apartado es dejar sentada nuestra posición, sobre cuáles son las caraterísticas que debe revestir el personaje que hemos llamado en este trabajo "el tercero mercantil de fe pública registral", estableciendo que a partir de la reunción conjunta de los correspondientes requisitos, merecerá protección absoluta por parte del ordenamieto jurídico.

Entrados de lleno en materia, habrá de omitir el desarrollo del tercero registral regulado en el artículo $2014^{\circ}$ del código civil, pues ciertamente poco o nada tiene que ver con el personaje que surge a partir del registro mercantil. Así entonces, advertimos que la única norma que regula el principio de fe pública registral en materia societaria es el artículo $4^{\circ}$ del Título Preliminar del Reglamento del Registro de Sociedades, aprobado por la Sunarp mediante la Resolución No 200-2001-SUNARP-SN en el año 2001, la cual literalmente reza que 
La inexactitud o invalidez de los asientos de inscripción del Registro no perjudicará al tercero que de buena fe hubiere celebrado actos jurídicos sobre la base de los mismos, siempre que las causas de dicha inexactitud o invalidez no consten en los asientos registrales

En términos generales, estamos de acuerdo con el tenor del artículo, pues consideramos que recoge adecuadamente el contenido básico del principio de fe pública registral; sin embargo también estamos de acuerdo en que dicha norma debe abrogarse, y de no abrogarse, los jueces debieran inaplicarla ejerciendo su potestad constitucionalmente reconocida del control difuso. La razón es muy simple: No existe en el ordenamiento jurídico peruano ninguna ley o norma con rango de ley, que haya normado la fe pública registral aplicable al Registro Mercantil. ${ }^{8}$

El hecho de que figure en el artículo $2014^{\circ}$ del código civil regulada la fe pública registral, en la parte de disposiciones generales, no implica que dicho principio es aplicable a todos los registros jurídicos llevados por la Sunarp. Efectivamente, de una simple lectura del artículo mencionado líneas arriba, se desprende que se trata de un principio de aplicación exclusiva para el registro de bienes, en el cual se establece una conexión lineal entre dos relaciones jurídicas -que involucran a tres partes-, donde una adquiere un derecho vía tracto sucesivo de aquella que figura legitimada para disponer del derecho. Siendo así, el artículo $2014^{\circ}$ del código sustantivo está mal ubicado, pues debe salir de las Disposiciones Generales y ubicarse en las normas atinentes a los registros de bienes.

Conforme a Gonzales Barrón (2013)

Tampoco puede aducirse el artículo $2014^{\circ} \mathrm{CC}$, que está pensado exclusivamente para los registros de bienes, pues el tercero protegido esel subadquirente en una cadena de transmisiones, todas inscritas, en donde el acto previo es nulo. En un registro de personas, por el contrario, solo se inscriben hechos de la misma persona, y los terceros toman en consideración esos datos para decidir si contratan

8 Siendo que la Sunarp no da visos de abrogar el artículo IV del Título Preliminar el Reglamento del Registro de Sociedades, debería modificarlo urgentemente para que sea acorde al nuevo artículo $2014^{\circ}$ del código civil, el cual prevé en virtud a la Ley $N^{\circ} 30313$ que la publicidad material se extiende no sólo a los asientos registrales, sino también a los títulos archivados. 
o no; pero las adquisiciones sucesivas que se realizan no tienen acceso en este tipo de Registro. Por tal razón, el artículo $2014^{\circ}$ no puede aplicarse. (p.108)

Así las cosas, consideramos saludable regular en el ordenamiento jurídico peruano la fe pública registral en el registro mercantil, pero a nivel de norma con rango de ley; definitivamente un reglamento no es el medio jurídico apropiado para romper con la sanción decretada por el derecho común en materia de nulidades, con la subsecuente ineficacia del acto declarado nulo; en buena cuenta, el Superintendente de un organismo estatal está modificando el código civil, lo cual resulta inadmisible.

Esta problemática y/o tentación de dar mayores alcances de los que tiene a un reglamento (en este caso, un reglamento de inscripciones de la Sunarp), no es nueva y ocurre en otras latitudes. De Eizaguirre (1999) justifica la necesidad de respetar la pirámide normativa

Porque los referidos aspectos sustantivos, en particular los relativos a la publicidad material (infra, V), constituyen excepciones a la básica norma de la relatividad de efectos de los contratos (art. $1257 \mathrm{CC}$ ), nos referiremos siempre en esta materia a normas del CCom, de igual rango legal. De tal suerte nos apartamos de la práctica viciosa de referir la publicidad legal a normas de orden reglamentario exclusivamente. No en balde señaló TS del 8 de junio de 1978/ActC 2534, "que una extensa jurisprudencia de esta Sala tiene declarado que los preceptos de un Reglamento por sí mismos, sin invocación de los de la Ley que desarrollan, no pueden tomarse como base de impugnación en un recurso por infracción de Ley".

Hoy día por supuesto, el Código de comercio español regula la fe pública registral mercantil en su artículo 20.2 y luego el Reglamento del registro mercantil la recoge en su artículo $8^{\circ}$.

Nuestra propuesta va entonces por incorporar en el código de comercio o en la Ley General de Sociedades el principio de fe pública registral, el cual sí merece considerarse en el ordenamiento jurídico de nuestro país a la luz de su fundamento principal que es la apariencia jurídica, pero que parte de un acto o hecho declarado nulo, donde lo que se privilegia es el tráfico jurídico personificado en el tercero que confió en la exactitud y/o validez de lo que publicitaba el Registro. 
Como hemos mencionado al finalizar el apartado anterior, es presupuesto para que se aplique la fe pública registral, la declaración de inexactitud o nulidad del hecho inscrito en el registro mercantil, pues si así no fuera, en principio, por legitimación registral estaríamos ante un caso de mera oponibilidad de lo inscrito frente al tercero y no de fe pública registral. En ejemplo muy simple servirá para graficar lo expuesto: Una empresa acuerda otorgar poder a " $X$ " para que venda un cuadro famoso, el cual fue adquirido por "Y"; si con posterioridad se declara nulo el acuerdo de apoderamiento, "Y" será mantenido en su derecho por haber confiado en que el Registro publicitaba un hecho válido. Pero si no se llega a declarar nulo el acuerdo de apoderamiento otorgado a "X", no se activará el principio de fe pública registral, y sí más bien el de oponibilidad registral.

Seguidamente entonces, y a partir de las idea de diversos autores, pasaremos a detallar cuáles serían los presupuestos necesarios para la aplicación del Principio de Fe Pública Registral en el Registro Mercantil, siempre dentro del marco normativojerárquico que estamos reclamando:

a) Debe existir una declaración de nulidad o inexactitud de lo inscrito y que sirvió de basamento al tercero para celebrar acto (s) jurídico (s).

b) El tercero registral no tiene que inscribir su derecho en ningún registro para merecer protección; piénsese en el ejemplo de quien compra el cuadro de un pintor famoso, cuyo derecho de propiedad no se inscribe en ningún registro jurídico a cargo de la Sunarp. Conforme a Casado Urbano (2002)

Al tercero le basta la adquisición, sin necesidad, a diferencia de lo exigido por el artículo 34 de la Ley Hipotecaria, de que inscriba su adquisición en el Registro Mercantil, lo que en la casi totalidad de supuestos, le sería imposible por la propia naturaleza de este Registro.” (p.323)

c) Para ser protegido el tercero registral al cual estamos aludiendo, no debe existir otra protección registral preferente. Casado Urbano (2002) desarrolla un ejemplo interesante que simplificamos en el sentido de que, una persona " $A$ " adquiere un predio de el apoderado de una sociedad, cuyo apoderamiento es declarado nulo posteriormente; si este apoderado hubiera vendido a varias personas ("B", "C" y "D") el mismo predio, a pesar de ser "A" tercero registral mercantil, no podría invocar amparo si "C" hubiera inscrito su adquisición, 
quien será amparada además por la fe pública registral del artículo 2014 del código civil (p. 333).

d) El tercero debe ser de buena fe, es decir que

En el caso de inscripción inexacta o nula la buena fe, requerida por el artículo 20

II CCom, consiste en el desconocimiento de tales circunstancias, que el RM por su deficiente contenido no revela. Para quebrar la buena fe se exige conocimiento positivo, sin que baste la culpa grave del tercero. (De Eizaguirre, 1999 , p. 242)

Esta buena fe sin embargo, implica que no debe constar en el registro la causa de nulidad o irregularidad (Gonzales Barrón, 2013, p.126)

e) La actuación del tercero debe ser negocial; es decir, que lo que se protege son los actos jurídicos celebrados por dicho tercero. Así, se descarta la apliación del principio si se adquiere algún derecho en virtud a ley, o por responsabilidad extracontactual.

f) El tercero debe tener conocimiento del supuesto base de apariencia. Dada la dificultad, sin embargo, de acreditar esta circunstancia, a fin de no devaluar el alcance protector de las normas en cuestión, se presume que el tercero conoce el contenido del RM. (De Eizaguirre, 1999, p. 243)

g) Debe existir nexo causal entre lo declarado inexacto o nulo y la respectiva adquisición de derechos;

Es decir, se requiere para que se otorgue el amparo de la fe pública, qe exista dependencia entre ambas relaciones, en el sentido de que pueda afirmarse que la situación que reflejaba el Registro ha sido uno de los factores decisivos de la adquisición de los derechos que ahora no pueden verse perjudicados por la declaración de inexactitud o nulidad del correspondiente asiento registral. (Casado Urbano, 2002, p. 331)

h) El sujeto que sufre la nulidad (sociedad) debe haberla provocado por culpa o dolo, esto es, debe serle imputable. Y añade Gonzales Barrón (2013) que ésta es la razón justificativa para que la protección se desplace de una víctima (que dio lugar a la nulidad, por su negligencia) a otra (que moralmente debe ser 
protegida por su buena fe) (p. 127). Por lo dicho, ante una falsificación se debe proteger a la Sociedad antes que al tercero.

i) No se requiere onerosidad en la adquisición del tercero; varias son las razones que abonan a favor de este argumento; uno de ellos es lo reseñado en el acápite anterior, en el sentido de que siendo imputable a la sociedad la declaración de nulidad de lo inscrito, debe protegerse "al no responsable", sea su adquición a título oneroso o gratuito. No hay que olvidar que existen argumentos bastante sólidos para proteger las adquisiciones gratuitas; así, García García (1993) nos recuerda que

Desde que una finca entra en el patrimonio de una persona ello le sirve para articular un modo de actuación con los acreedores, y puede salir muy perjudicado si se le desvanecen todas las perspectivas que le permitía su [nuevo] patrimonio, pudiéndole llevar injustamente a la ruina (p. 285); más aún, habría que proteger al tercero si a la sociedad le es imputable la nulidad declarada.

En abono de excluir la onerosidad como presupuesto de protección al tercero, Casado Urbano (2002) nos dice que "con exclusión de los supuestos de herencia, en los que, como acabamos de ver, ni siquiera surge el tercero civil, la adquisición puede serlo a título gratuito u oneroso." (p. 325) y añade luego que "Consecuencia de esta heterogeneidad de una y otra relación es que en el campo registral mercantil no se exige, ni puede exigirse al adquirente a proteger...que la misma lo sea a título oneroso" (p. $331)$.

Finalmente, a propósito de nuestra propuesta para que se abrogue el artículo IV del Título Preliminar del Reglamento del Registro Mercantil, pasa también por considerar -además del problema jerárquico normativo-, que con las últimas modificaciones efectuadas a nivel notarial (D.S. 006-2013-JUS) y sus modificatorias, así como la Ley $\mathrm{n}^{\circ}$ 30313, en virtud a las cuales se otorga mayores seguridades a las actas y a sus respectivas copias certificadas en que se asientas los acuerdos adoptados por las personas jurídicas, y a propósito de las responsabilidades penales para los Gerentes Generales de las sociedades mercantiles, entre otros, consideramos que hay mayor seguridad en los actos que se registran, propendiendo a su exactitud y validez. Ya en su momento, el propio Ehrenberg dice "que la experiencia muestra que en la infinita mayoría de los casos se causan inscripciones exactas y legales” (como se citó en Garrigues, 1984, p. 715). 
Habrá que evaluar en sede judicial cuántas veces ha habido necesidad de recurrir al artículo IV que venimos comentando; más todavía porque la propia Ley General de Sociedades prevé la aplicación del Principio de Fe Pública Registral en determinados casos particulares (véase el artículo 148, entre otros). 


\section{CONCLUSIONES}

- Debe reconocerse la diferencia existente entre los Registros jurídicos de "bienes" y los Registros jurídicos de "personas" en cuanto a su naturaleza y objeto; en atención a ello, debe descartarse la importación de los Principios Registrales de un registro hacia otro sin discriminar su contenido.

- El Registro Mercantil está diseñado básicamente para informar con efectos jurígenos a los terceros, pues la o las partes deben cumplir los términos en los cuales se han vinculado, en atención a la mera existencia de la relación jurídica existente y no por la publicidad que efectúa el Registro.

- La Teoría de la Apariencia figura en diversas normas del Código Civil y la Ley General de Sociedades, y sostiene a los dos terceros registrales del registro mercantil: por un lado, el tercero registral mercantil de oponibilidad, y del otro, el tercero mercantil de fe pública registral.

- El tercero registral del Registro Mercantil es totalmente distinto al del Registro de la Propiedad, siendo el antes que un tercero, un segundo, pues se vincula directamente con la sociedad o partir de las inscripciones de ésta.

- El Código de Comercio peruano regula en su artículo $26^{\circ}$ la oponibilidad registral, la cual es la otra cara de la inoponibilidad registral. Consideramos que debe desarrollarse a cabalidad ambos principios en esta norma, identificando los presupuestos para su aplicación.

- La Fe Pública Registral regulada en el Registro Mercantil peruano no tiene asidero legal, pues no ha sido normada ni en el Código de Comercio, ni en la Ley General de Sociedades, motivo por el cual consideramos que debe abrogarse del Reglamento del Registro de Sociedades aprobado por la Sunarp. Sin perjuicio de esta patología normativa en la regulación del Principio de Fe Pública Registral, consideramos que sí debe aprobarse, pero en una norma con rango de ley. 


\section{RECOMENDACIONES}

- Teniendo en cuenta que la Ley General de Sociedades no regula el Registro Mercantil, como sí lo hace nuestro viejo -aunque vigente- Código de Comercio, consideramos que debería revisarse las normas del código para actualizarlas conforme a los preceptos de la LGS, que es norma mucho más moderna.

- Se debe abrogar el artículo IV del Título Preliminar del Reglamento del Registro de Sociedades.

- En el supuesto de no abrogarse el artículo citado en el numeral anterior, deberá modificarse el mismo a fin que sea acorde a lo previsto en la Ley $\mathrm{N}^{\circ} 30313$, en virtud a la cual la publicidad material no sólo se extiende a los asientos del Registro, sino también a los títulos archivados.

- Debería regularse el principio de fe pública registral en la parte general de la Ley General de Sociedades.

- Se debe modificar la ubicación del artículo $2014^{\circ}$ del código civil pues el mismo está ubicado en las disposiciones generales del libro IX de dicho cuerpo normativo, cuando en realidad es un Principio Registral adscrito únicamente a los registros de bienes. 
Álvarez Caperochipi, J. (2005). Propiedad y derechos reales (Vol. 1). Granada, España: Comares.

Arias Schreiber Pezet, M. (2006). Exégesis del Código Civil de 1984 (Vol. 2). Lima: Gaceta Jurídica.

Falzea, Á. (2006). El principio jurídico de la apariencia. Derecho PUCP: Revista de la Facultad de Derecho, (59), 177-212. Recuperado de http://revistas.pucp.edu.pe/index.php/derechopucp/index

Cabanellas, G. (1989). Diccionario enciclopédico de derecho usual (21. ${ }^{\mathrm{a}} \mathrm{ed} ., \mathrm{V}$.l. 7). Buenos Aires: Heliasta.

Casado Urbano, P. (2002). Los principios registrales mercantiles. Madrid: Colegio de Registradores de la Propiedad y Mercantiles de España.

Código Civil. (2014). Lima: Jurista Editores.

De Eizaguirre, J. (1999). Derecho mercantil (2. ${ }^{\text {e }}$ ed.). Madrid: Civitas.

De los Ríos Sánchez, J. M. (2014). Publicidad legal: registro mercantil y registro de bienes muebles. En J. M. De la Cuesta Rute (Dir.), Derecho mercantil I (2. a ed., pp. 219-230). Barcelona: Huygens.

Elías Laroza, E. (1999). Derecho societario peruano: la Ley General de Sociedades. Trujillo, Perú: Normas Legales.

García García, J. (1993). Derecho inmobiliario registral o hipotecario (Vol. 2). Madrid: Civitas.

Garrigues, J. (1984). Curso de derecho mercantil (Vol. I). México D.F.: Porrúa.

Gonzales Barrón, G. (2013). Manual práctico de la Ley General de Sociedades (3. ${ }^{a}$ ed.). Lima: San Marcos.

Gonzales Loli, J. (2010). Protección al tercero registral societario. En A los 12 años de la Ley General de Sociedades (pp. 227 - 259). Lima: Grijley.

González-Meneses García-Valdecasas, M. (2005). Principios y fundamentos del registro mercantil. En J. F. Delgado de Miguel (Coord.), Instituciones de derecho privado: mercantil, derecho mercantil especial (T. 5, Vol. 6, pp. 267394). Navarra: Aranzadi.

Lehmann, H. (s. f.). Tratado de derecho civil: parte general (Vol. 1). Madrid: Revista de Derecho Privado.

Madriñan de la Torre, R. y Prada Márquez, Y. (2013). Principios de derecho comercial (11. ${ }^{\mathrm{a}}$ ed.). Bogotá: Temis.

Pau Pedrón, A. (2001). La publicidad registral. Madrid: Colegio de Registradores de la Propiedad y Mercantiles de España. 
Real Academia Española. (2014). Diccionario de la lengua española. Recuperado de http://www.rae.es/

Rojo, Á. (2004). El registro mercantil. En A. Menéndez (Dir.), Lecciones de derecho mercantil (2. ${ }^{\mathrm{a}}$ ed., pp. 103-123). Madrid: Civitas.

Uría, R. (1987). Derecho mercantil (14. ${ }^{a}$ ed.). Madrid: Marcial-Pons.

Vicent Chuliá, F. (2006). Introducción al derecho mercantil (19. ${ }^{a}$ ed.). Valencia: Tirant Lo Blanch. 


\section{BIBLIOGRAFÍA}

Beaumont Callirgos, R. (2006). Comentarios a la Ley General de Sociedades (6. ${ }^{\mathrm{a}}$ ed.). Lima: Gaceta Jurídica.

Castillo Delgado, G. (2000). Registro de personas jurídicas. En Superintendencia Nacional de los Registros Públicos (Ed.), Temas de derecho registral (T. 3, pp. 387-403). Lima: Palestra.

Jerez Delgado, C. (2005). La buena fe registral. Madrid: Colegio de Registradores de la Propiedad, Mercantiles y Bienes Muebles de España.

Legislación comercial. (2014). Lima: Jurista Editores.

Legislación hipotecaria y del registro Mercantil (28. ${ }^{a}$ ed.). (2007). Navarra: Aranzadi

Macedo, O. (2001). Lecciones de derecho comercial. Lima: Universidad Inca Garcilaso de la Vega.

Messineo, F. (1971). Manual de derecho civil y comercial (Vol. 5, Trad. S. S. Melendo). Buenos Aires: Ediciones Jurídicas.

Morales de la Cruz, R. (2002). Manual del Reglamento del Registro de Sociedades. Lima: Graphic.

Hundskopf, O. (enero del 2013). El acto no inscribible en el Registro de Sociedades. Actualidad Jurídica, (230), 385-391.

Hundskopf, O. (julio del 2015). El cuadro de accionistas no es inscribible en la partida registral de una sociedad anónima cerrada. Diálogo con la Jurisprudencia, (202), 241-252.

Reglamento de Registro Mercantil aprobado por la Corte Suprema de Justicia en Sesión de Sala Plena de 15 de mayo de 1969. (s. f.). Lima: Gonzalo Hidalgo Iberico.

Rodriguez Rodriguez, J. (1980). Curso de derecho mercantil (15. a ed., Vol. 1). México D.F.: Porrúa.

Santa Cruz Vera, A. (1999). El principio de tracto sucesivo y el registro de personas jurídicas (mercantil). En Superintendencia Nacional de los Registros Públicos (Ed.), Temas de derecho registral (Vol. 4, pp. 101-109). Lima: Sunarp.

Tribunal Registral de la Sunarp. (2010). Jurisprudencia registral sobre personas jurídicas. Lima: Gaceta Jurídica. 